\title{
Revision of the amphiamerican genus Mysidium Dana, 1852 (Crustacea: Mysida: Mysidae), with descriptions of two new species and the establishment of two new subgenera
}

\author{
Karl J. WITTMANN ${ }^{1, *}$ \& Peter WIRTZ ${ }^{2}$ \\ ${ }^{1}$ Department of Environmental Health, Medical University of Vienna, \\ Kinderspitalgasse 15, A-1090 Vienna, Austria. \\ ${ }^{2}$ Centro de Ciências do Mar, Universidade do Algarve, Campus de Gambelas, \\ PT-8005-139, Faro, Portugal. \\ *Corresponding author: karl.wittmann@meduniwien.ac.at \\ 2Email: peterwirtz2004@yahoo.com \\ ${ }^{1}$ urn:1sid:zoobank.org:author:C90E7BC4-A27A-4B41-93F3-6224D17795FF \\ ${ }^{2}$ urn:lsid:zoobank.org:author:A9870EB6-74E9-43C7-931E-A23AF2E981DA
}

\begin{abstract}
Revised definitions are given for the genus Mysidium Dana, 1852, and its eight previously known species, based on material from Curaçao, Bonaire and SE-Brazil, along with the evaluation of published data. Type material of Diamysis columbiae Zimmer, 1915, M. cubanense Băcescu \& Ortiz, 1984 and M. rubroculatum Băcescu \& Ortiz, 1984 is examined. A lectotype is designated for D. columbiae Zimmer, 1915, a senior synonym of Mysidium columbiae (Zimmer, 1915). Two new species are described, M. triangulare Wittmann sp. nov. from Curaçao and M. antillarum Wittmann sp. nov. from Curaçao and Bonaire. Known ranges are extended by first records of $M$. cubanense from Curaçao and Bonaire and of M. integrum W.M. Tattersall, 1951 from SE Brazil. Three morphologically different groups are established at the subgeneric level: (1) the nominotypical subgenus Mysidium Dana, 1852 with $M$. gracile (Dana, 1852), M. integrum, M. cubanense, M. rubroculatum and M. triangulare sp. nov. from the West Atlantic plus M. rickettsi Harrison \& Bowman, 1987 from the East Pacific; (2) Occimysidium Wittmann subgen. nov. represented only by M. pumae Ortiz, Hendrickx \& Winfield, 2017 from the Pacific coast of Mexico; and finally (3) Orientomysidium Wittmann subgen. nov. comprising M. columbiae and M. antillarum sp. nov. from the West Atlantic. The poorly known M. iliffei Băcescu, 1991 is not assigned to any subgenus. A key to the resulting three subgenera and ten nominal species of the genus Mysidium is given.
\end{abstract}

Keywords. Taxonomy, first description, key to species, range extensions, subtropical to tropical West Atlantic.

Wittmann K.J. \& Wirtz P. 2019. Revision of the amphiamerican genus Mysidium Dana, 1852 (Crustacea: Mysida: Mysidae), with descriptions of two new species and the establishment of two new subgenera. European Journal of Taxonomy 495: 1-48. https://doi.org/10.5852/ejt.2019.495

\section{Introduction}

Species of the genus Mysidium Dana, 1852, constitute the most frequent shrimp-like, swarming crustaceans with an adult body size of 3-9 mm, inhabiting mangrove and shallow coral-reef habitats of the Gulf of 
Mexico, Caribbean and elsewhere in near-shore marine habitats between Bermuda and Rio de Janeiro (Steven 1961; Goodbody 1965; Emery 1968; Modlin 1987, 1990, 1993). Six species have so far been described from the subtropical to tropical coasts of the West Atlantic (Dana 1852; Zimmer 1915a; W.M. Tattersall 1951; Băcescu \& Ortiz 1984; Băcescu 1991) and two additional species from the Pacific coast of Mexico (Harrison \& Bowman 1987; Ortiz et al. 2017a). The importance of this genus is underlined by the many studies on its physiology (Bainbridge \& Waterman 1957, 1958; Waterman 1960; Buskey 2000), behaviour (Steven 1961; Jander 1962; McFarland \& Kotchian 1982; Hahn \& Itzkowitz 1986; Modlin 1987, 1990; Buskey 1998; Twining et al. 2000), morphogenesis (Duman-Scheel \& Patel 1999; DumanScheel et al. 2002), marsupial development (Davis 1966; Whittington 2004), population dynamics (Goodbody 1965; Modlin 1993; Prieto et al. 2009), trophic ecology (McFarland \& Kotchian 1982; Ambler et al. 1994; Bullard \& Hay 2002), biodiversity (Price \& Heard 2009), biogeography (EscobarBriones \& Soto 1991) and taxonomy (Dana 1852; Zimmer 1915a; W.M. Tattersall 1951; Brattegard 1969, 1970, 1975; Băcescu \& Ortiz 1984; Harrison \& Bowman 1987; Modlin 1990, 1993; Băcescu 1991; Price \& Heard 2009; Ortiz et al. 2012, 2017b; Miyashita \& Calliari 2014; Ortiz \& Lalana 2018).

Due to the large numbers and sizes of swarms in near-shore habitats, together with their exclusively amphiamerican distribution range, it is unsurprising that these crustaceans constituted the first mysid genus described as endemic to America (Dana 1850). The original generic definition given by Dana for the junior homonym Mysidia in 1850, renamed by him as Mysidium in retrospective formulation (see Discussion) in 1852 , was very brief as was usual for that period. Many more details became available by subsequent descriptions and supplementary definitions of the genus by Czerniavsky (1887) and Ortiz et al. (2017b). Detailed species descriptions were provided by Dana (1852), Zimmer (1915a), W.M. Tattersall (1951), Harrison \& Bowman (1987) and Ortiz et al. (2017a, 2017b). The first descriptions of M. cubanense Băcescu \& Ortiz, 1984, M. rubroculatum Băcescu \& Ortiz, 1984 and M. iliffei Băcescu, 1991 were also rather brief, complicating the separation of M. cubanense and M. rubroculatum from M. gracile (Dana, 1852) and M. integrum W.M. Tattersall, 1951. In diagnoses and key to species, Ortiz et al. (2017a, 2017b) and Ortiz \& Lalana (2018) introduced numbers of setae on the endopod of the fourth male pleopod as supplementary measures of discrimination. Nonetheless, the diagnostic resolution is lowered, but not suspended, by the below documented inter-individual variability of these numbers. Based on the study of types and of additional material from a wide distribution range, the present contribution improves the discriminatory performance by determining additional discriminatory features and by applying a consistent, clear-cut scheme of characters at the genus, subgenus and species level. This led to the detection of new species together with the establishment of new subgenera.

\section{Material and methods}

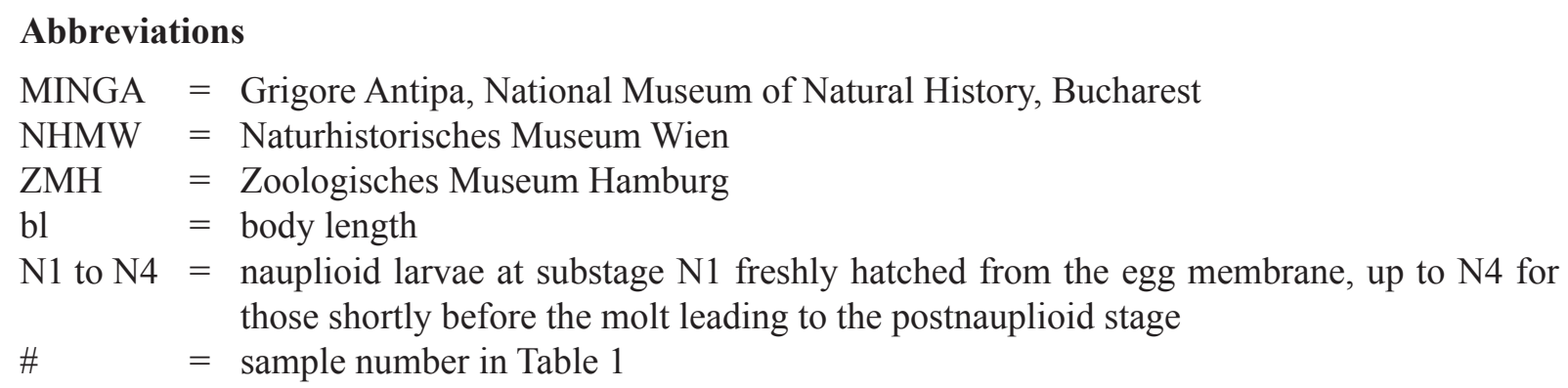

\section{Material}

A total of 13 samples were taken with hand net by snorkeling and scuba diving by one of us (Peter Wirtz) in littoral and sublittoral marine waters of Curaçao, Bonaire and SE-Brazil (Table 1). Additional material was obtained upon request from museum collections: the Zoological Museum of Hamburg kindly provided the types of Diamysis columbiae Zimmer, 1915. The Grigore Antipa, National 
Table 1. Sampling data of species of Mysidium Dana, 1852 in euhaline coastal waters of Curaçao, Bonaire and SE-Brazil.

\begin{tabular}{|c|c|c|c|c|c|c|}
\hline $\begin{array}{l}\text { Sample } \\
\text { no. }\end{array}$ & Locality & Coordinates & $\begin{array}{c}\text { Depth } \\
(\mathbf{m})\end{array}$ & Sample details & $\begin{array}{l}\text { Date } \\
\text { (time) }\end{array}$ & $\begin{array}{l}\text { Species encoun- } \\
\text { tered }\end{array}$ \\
\hline C1 & $\begin{array}{l}\text { Curaçao, close to Piscadera } \\
\text { Baai, in front of Caribbean } \\
\text { Marine Biological Institute }\end{array}$ & $\begin{array}{l}12.1222^{\circ} \mathrm{N} \\
68.9690^{\circ} \mathrm{W}\end{array}$ & 0.2 & $\begin{array}{l}\text { Swarm above rubble formed by } \\
\text { dead branches of Acropora sp. }\end{array}$ & $\begin{array}{l}18 \text { Aug. } 1997 \\
\text { (day) }\end{array}$ & M. antillarum \\
\hline $\mathbf{C 2}$ & $\begin{array}{c}\text { Curaçao, harbour at entrance } \\
\text { of Piscadera Baai }\end{array}$ & $\begin{array}{l}12.1288^{\circ} \mathrm{N} \\
68.9695^{\circ} \mathrm{W}\end{array}$ & $0.5-2$ & Swarm around pier & $\begin{array}{l}18 \text { Aug. } 1997 \\
\text { (day) }\end{array}$ & M. antillarum \\
\hline C3 & $\begin{array}{l}\text { Curaçao, } 1 \mathrm{~km} \text { west of } \\
\text { Piscadera Baai }\end{array}$ & $\begin{array}{l}12.1285^{\circ} \mathrm{N} \\
68.9792^{\circ} \mathrm{W}\end{array}$ & $4-12$ & Swarms around blocks of corals & $\begin{array}{l}20 \text { Aug. } 1997 \\
\text { (day) }\end{array}$ & $\begin{array}{l}\text { M. cubanense } \\
\text { M. triangulare } \\
\text { M. columbiae }\end{array}$ \\
\hline $\mathrm{C} 4$ & Curaçao, as in $\mathrm{C} 1$ & as in $\mathrm{C} 1$ & $0-0.5$ & $\begin{array}{l}\text { Swept with hand net in front of } \\
\text { diver's torch close to sea floor }\end{array}$ & $\begin{array}{l}21 \text { Aug. } 1997 \\
\text { (night) }\end{array}$ & $\begin{array}{l}\text { M. cubanense } \\
\text { M. antillarum }\end{array}$ \\
\hline C5 & Curaçao, Reef Sint Marie & $\begin{array}{l}12.2119^{\circ} \mathrm{N} \\
69.0867^{\circ} \mathrm{W}\end{array}$ & 7 & Swarms between corals & $\begin{array}{l}22 \text { Aug. } 1997 \\
\text { (day) }\end{array}$ & $\begin{array}{l}\text { M. cubanense } \\
\text { M. columbiae }\end{array}$ \\
\hline C6 & Curaçao, Reef Sint Marie & $\begin{array}{l}12.2122^{\circ} \mathrm{N} \\
69.0850^{\circ} \mathrm{W}\end{array}$ & $0-0.5$ & $\begin{array}{c}\text { Swarms around pier and off } \\
\text { pier, immediately below surface }\end{array}$ & $\begin{array}{l}23 \text { Aug. } 1997 \\
\text { (day) }\end{array}$ & $\begin{array}{l}\text { M. integrum } \\
\text { M. antillarum }\end{array}$ \\
\hline C7 & Curaçao, Vaersenbaai & $\begin{array}{l}12.1606^{\circ} \mathrm{N} \\
69.0056^{\circ} \mathrm{W}\end{array}$ & $25-35$ & Swarms between corals & $\begin{array}{l}23 \text { Aug. } 1997 \\
\text { (day) }\end{array}$ & $\begin{array}{l}\text { M. gracile } \\
\text { M. integrum } \\
\text { M. antillarum }\end{array}$ \\
\hline C8 & Curaçao, Playa Lagun & $\begin{array}{l}12.3181^{\circ} \mathrm{N} \\
69.1511^{\circ} \mathrm{W}\end{array}$ & $4-6$ & $\begin{array}{c}\text { Pooled sample from large } \\
\text { swarm between corals }(4 \mathrm{~m}) \text {, } \\
\text { loose aggregation above sand } \\
(6 \mathrm{~m}) \text {, and mysids scattered } \\
\text { above sand inside small cave } \\
(5 \mathrm{~m})\end{array}$ & $\begin{array}{l}28 \text { Aug. } 1997 \\
\text { (day) }\end{array}$ & $\begin{array}{l}\text { M. cubanense } \\
\text { M. triangulare } \\
\text { M. antillarum }\end{array}$ \\
\hline C9 & Curaçao, Playa Kalki & $\begin{array}{l}12.3756^{\circ} \mathrm{N} \\
69.1581^{\circ} \mathrm{W}\end{array}$ & 0.05 & $\begin{array}{l}\text { Swarms above algae in the } \\
\text { breaker zone }\end{array}$ & $\begin{array}{l}30 \text { Aug. } 1997 \\
\text { (day) }\end{array}$ & M. integrum \\
\hline $\mathrm{C10}$ & Curaçao, Playa Santu Preto & $\begin{array}{l}12.3033^{\circ} \mathrm{N} \\
69.1489^{\circ} \mathrm{W}\end{array}$ & 1 & $\begin{array}{c}\text { Large swarms freely swimming } \\
\text { in front of and in the entrance } \\
\text { area of cave }\end{array}$ & $\begin{array}{l}31 \text { Aug. } 1997 \\
\text { (day) }\end{array}$ & $\begin{array}{l}\text { M. integrum } \\
\text { M. triangulare } \\
\text { M. antillarum }\end{array}$ \\
\hline B11 & Bonaire, Bachelor's Beach & $\begin{array}{l}12.1260^{\circ} \mathrm{N} \\
68.2877^{\circ} \mathrm{W}\end{array}$ & $3-26$ & $\begin{array}{l}\text { Pooled sample from the sea } \\
\text { floor }\end{array}$ & $\begin{array}{l}7 \text { June } 2004 \\
\text { (day) }\end{array}$ & $\begin{array}{l}\text { M. gracile } \\
\text { M. cubanense } \\
\text { M. columbiae } \\
\text { M. antillarum }\end{array}$ \\
\hline B12 & $\begin{array}{c}\text { Bonaire, in front of dive } \\
\text { base Dive Inn }\end{array}$ & $\begin{array}{l}12.1460^{\circ} \mathrm{N} \\
68.2767^{\circ} \mathrm{W}\end{array}$ & 9 & $\begin{array}{l}\text { Swept with hand net in front of } \\
\text { diver's torch close to sea floor }\end{array}$ & $\begin{array}{l}10 \text { June } 2004 \\
\text { (night) }\end{array}$ & $\begin{array}{l}\text { M. gracile } \\
\text { M. columbiae }\end{array}$ \\
\hline F13 & $\begin{array}{l}\text { Brazil, off Cabo Frio, Ilha } \\
\text { dos Papageios }\end{array}$ & $\begin{array}{l}22.8974^{\circ} \mathrm{S} \\
41.9834^{\circ} \mathrm{W}\end{array}$ & $4-12$ & $\begin{array}{l}\text { Pooled sample from very large } \\
\text { mysid swarms }\end{array}$ & $\begin{array}{l}6 \text { Feb. } 2003 \\
\text { (day) }\end{array}$ & $\begin{array}{l}\text { M. gracile } \\
\text { M. integrum }\end{array}$ \\
\hline
\end{tabular}

Museum of Natural History, Bucharest, provided types of Mysidium cubanense Băcescu \& Ortiz, 1984, and M. rubroculatum Băcescu \& Ortiz, 1984. Types of newly described species are deposited at MINGA, NHMW and ZMH.

\section{Laboratory methods}

Preparation, measurements and examination of materials as in Wittmann (2008). Body length (bl) measured according to Tattersall \& Tattersall (1951) from the anterior margin of the carapace to the posterior margin of the telson, excluding the spines. Note in the present context that Băcescu \& Ortiz (1984) measured according to Băcescu (1954) from the tip of the antennal scale to the end of the exopod of uropods without setae. Length measurements of somites, appendages and segments do not include 
setae, laminae, spines, claws, etc. The length of the antennular trunk and its segments is measured along the dorsal midline. Size ratios within and between angular and oblique objects were calculated as linearized within a single observation plane; this is especially important for estimating the relative size of eyes. The easily confounded, large intersegmental joint between the basis and flagellum of the thoracic exopods was excluded from counts of segmental numbers. The statolith mineral was determined according to Wittmann et al. (1993). Juveniles and immatures are not represented in material lists below.

\section{Terminology}

Essentially as in Wittmann et al. (2014). In the present context, note that thorn-like projections with a basal suture are termed 'spines', those without suture are 'teeth' or 'denticles'; slender projections in dense series without suture are 'laminae'; slender, flexible projections with basal suture are 'setae', particularly if barbed or pinnate. The maxillula is obscurely three-segmented with inner lobe (endite) according to the interpretation by Tattersall \& Tattersall (1951). Terminology of gross structures of the foregut follows Kobusch (1998); modified spines of the foregut according to Wittmann \& Griffiths (2018), in addition, 'apically pronged, serrated' spines (Fig. 13G) are now distinguished. Marsupial stages are distinguished according to Wittmann (1981) and Wittmann et al. (2014). Post-marsupial stages are distinguished according to Wittmann et al. (2016). Drawings of sex-specific features are labeled by 9 - or $\delta$-symbols, respectively, in Figs 1-13. The absence of such labels implies missing or unapparent gender-specific differences.

\section{Taxonomy}

At subfamily to tribe levels adopted from Wittmann et al. (2014) with additions by Wittmann et al. (2016). Diagnoses and keys to species by Ortiz et al. (2017a, 2017b) provided a valuable starting point for the present revision of the genus Mysidium.

\section{Results}

\section{Taxonomy and large-scale distribution}

Order Mysida Boas, 1883

Family Mysidae Haworth, 1825

Subfamily Mysinae Haworth, 1825

Tribe Anisomysini Wittmann, Ariani \& Lagardère, 2014

\section{Diagnosis}

The diagnosis of this tribe is slightly modified from Wittmann et al. (2014) due to certain spine-like cuticle structures of the telson being now interpreted as laminae (see 'Methods' and species descriptions below):

Antennal scale setose all around (exceptionally with blunt spine on outer margin) and with short apical segment; carpopropodus of thoracic endopod 6 with 1-3 segments; two pairs of well-developed oostegites, rudimentary oostegite on thoracic endopod 6; pleopods rudimentary in both sexes, except male pleopod 4 and to a minor extent also pleopod 3; third male pleopod uniramous, unsegmented, mostly rudimentary as in females or reduced to small endopod fused with sympod; exopod of fourth male pleopod with total of 1-2 modified setae (1-2 on apical segment, $0-1$ on subapical segment); uropods without spines; telson shorter than ultimate pleonite, terminally entire or with apical cleft, lateral margins bare or furnished with spines or laminae; spines (if present) on lateral margins arranged in continuous series, not arranged in groups of large spines with smaller spines in between; telson always devoid of setae. 
Genus Mysidium Dana, 1852

Mysidia Dana, 1850: 130 (junior homonym, see Discussion).

Mysidium Dana, 1852: 638, 653 (published in synonymy, see Discussion).

Themisto - Dana 1850: 130 (quoted as homonym).

Macromysis - Dana 1852: 638, 652, 653 (subjective junior synonym, see Discussion); 1853: 1435; 1855: pl. 43, fig. 5. - Czerniavsky 1887: 85 (in synonymy). — Tattersall \& Tattersall 1951: 376 (in synonymy).

Mysidium - Czerniavsky 1882: 16, 50 (in key); 1887: 85 (diagnosis, synonymy). — W.M. Tattersall 1951: 223 (synonymy, key to species). — Brattegard 1969: 89 (key to species). — Mauchline 1980: 36 (in key). — Băcescu \& Ortiz 1984: 22 (key to species). — Harrison \& Bowman 1987: 678. — Fukuoka 2006: fig. 1. — Petrescu \& Wittmann 2009: 64. — Ortiz et al. 2012: 985; 2017b: 72. — Wittmann et al. 2014: 339. — Ortiz \& Lalana 2018: 67.

Mysidia - Czerniavsky 1887: 85 (in synonymy). — Gerstaecker \& Ortmann 1901: 665 (in citation). Zimmer 1915b: 211, 215; 1918: 24. — Illig 1930: 599 (in list).

Diamysis - Zimmer 1915a: 214 (invalid subsequent assignment).

\section{Type species}

Macromysis gracilis Dana, 1852, currently acknowledged in revised combination as Mysidium gracile (Dana, 1852).

\section{Diagnosis}

Compiled with the reservation that not every one of the following characters is known in Mysidium iliffei Băcescu, 1991 (see Discussion):

Anisomysini with eyes normal, eyestalks and cornea well developed. Antennular trunk terminally with the usual two flagella in both sexes, no accessory flagellum developed. Appendix masculina large, setose. Antennal scale lanceolate, without spines, but setose all around, with small terminal segment. Mandibles normal, palp three-segmented, cutting edges with well-developed pars incisiva, lacinia mobilis and pars molaris. Distal segment of maxillary palp with setae, but without denticles. Thoracopods essentially normal, endopods with 2- or three-segmented carpopropodus. All pleopods of females and pleopods $1-3,5$ of males are vestigial, setose, uniramous, unsegmented. Male pleopod 3 larger than pleopods 1-2, 5. Male pleopod 4 even longer, modified, with distinct sympod, unsegmented endopod and 3- or 4-segmented, slender exopod. Terminal two segments of exopod each bearing a large modified seta, remaining segments usually without setae, at most with one small seta on the basal segment. Uropods setose all around, without spines; exopods longer than endopods. Telson longer than broad, with entire or incised terminal margin; with spines and laminae on distal half.

\section{Etymology}

Derivation and gender of Mysidia and Mysidium not stated by Dana $(1850,1852)$. Neutral gender of Mysidium implicitly fixed by Czerniavsky (1887: 85) upon proposing the revised combination Mysidium gracile (Dana, 1852).

\section{Subgenera included}

Mysidium Dana, 1852, nominotypical subgen., east and west coasts of America

Orientomysidium Wittmann subgen. nov., east coast of America

Occimysidium Wittmann subgen. nov., west coast of America 


\section{Species included}

West Atlantic $\left(32^{\circ} \mathrm{N}\right.$ to $\left.24^{\circ} \mathrm{S}\right)$ :

Mysidium (Mysidium) gracile (Dana, 1852)

Mysidium (Mysidium) integrum W.M. Tattersall, 1951

Mysidium (Mysidium) cubanense Băcescu \& Ortiz, 1984

Mysidium (Mysidium) rubroculatum Băcescu \& Ortiz, 1984

Mysidium (Mysidium) triangulare Wittmann sp. nov.

Mysidium (Orientomysidium) columbiae (Zimmer, 1915) comb. nov.

Mysidium (Orientomysidium) antillarum Wittmann sp. nov.

Mysidium iliffei Băcescu, 1991

East Pacific $\left(21-25^{\circ} \mathrm{N}\right)$ :

Mysidium (Mysidium) rickettsi Harrison \& Bowman, 1987

Mysidium (Occimysidium) pumae Ortiz, Hendrickx \& Winfield, 2017 comb. nov.

Mysidium Dana, 1852, nominotypical subgenus

\section{Diagnosis}

Subdivision of the genus Mysidium Dana, 1852, characterized by three-segmented carpopropodus of third thoracic endopod. Merus of this endopod with non-serrated setae exclusively, with the reservation that this feature is unknown in M. rickettsi Harrison \& Bowman, 1987. Third male pleopod with medial widening at 40-60\% distance from basis. Sympod of fourth male pleopod without setae on rostral face. Its exopod four-segmented; the two proximal segments without setae; the two distal segments each with one unbranched modified seta. Telson entire, or at most with a rounded, shallow indentation.

\section{Distribution}

Littoral and sublittoral waters of Atlantic and Pacific coasts of subtropical to tropical America $\left(32^{\circ} \mathrm{N}\right.$ to $24^{\circ} \mathrm{S}$ ), including Caribbean, Gulf of Mexico and Gulf of California.

\section{Mysidium (Mysidium) gracile (Dana, 1852)}

Fig. 1

Macromysis gracilis Dana, 1852: 653-655 (senior synonym in combination with generic, subjective junior synonym).

Macromysis gracilis - Dana 1855: pl. 43, fig. 5a-m. — Smith 1873: 41 (in list). — Illig 1930: 599 (in synonymy).

Mysidium gracile-Czerniavsky 1887: 85-87 (revised combination). - W.M. Tattersall 1951: 222-223. — Costa 1964: 8. — Brattegard 1969: 80; 1970: 127; 1974b: 102; 1975: 112. — Almeida Prado 1974: 53. — Quintero \& Zoppi de Roa 1977: fig. 3. — Mauchline 1980: 338 (in list). — Băcescu \& Ortiz 1984: 22 (in key). — Zoppi de Roa et al. 1989: fig. 2C. — Murano 1999: fig. 6.89. — Twining et al. 2000: 1845. — Price et al. 2002: 45. — Price \& Heard 2004: 155; 2009: 938 (in list). — Ortiz et al. 2017a: table 1; 2017b: fig. 5. — Sorbe et al. 2007: table I. — Miyashita \& Calliari 2014: 9, table 1. — Wittmann et al. 2014: 298. — Esteves-Astudillo et al. 2017: fig. 5. — Ortiz \& Lalana 2018: 72.

Mysidia gracilis - Zimmer 1915b: 215 (subsequent combination with generic junior homonym); 1918: 24, figs 33-34.

Mysidia gracile - Illig 1930: 500 (as before, gender variant, in key). 


\section{Type material}

Not examined.

\section{Other material examined}

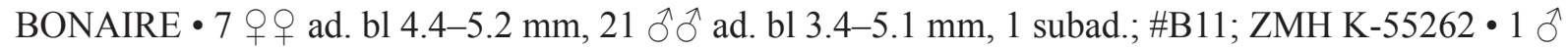
ad. bl 4.6 mm; \#B12; MINGA MYS 439.

CURAÇAO • 1 ô ad. bl 5.6 mm, 6 subad.; \#C7; MINGA MYS 434.

SE-BRAZIL • 19 우 ad. bl 4.8-6.3 mm, 15 ồ ad. bl 5.2-6.6 mm, 13 subad.; \#F13; NHMW 26482.

\section{Type locality}

(Sub)tropical SW-Atlantic, harbour of Rio de Janeiro (Dana 1852), about $22.90^{\circ} \mathrm{S}, 43.17^{\circ} \mathrm{W}$. The present sample off Cabo Frio is at about $145 \mathrm{~km}$ east along the shoreline from this harbour.

\section{Revised definition}

All features as diagnosed for the genus and its subgenus Mysidium Dana, 1852. Cornea globose in lateral view, calotte-shaped in dorsal view, with diameter 1.7-3.2 times as long as terminal segment of antennular trunk. Eyestalks smooth. Rostrum short, triangular, apically rounded to obtusely pointed, not extending beyond basis of eyestalks. Antero-lateral edges of carapace rounded. Only males with anterior margin of antennular trunk dorsally with rounded, shield-like, mediodistal extension (Fig. 1A-B); plumose seta at anterior margin of this extension showing 0.9-1.4 times extension length; longitudinal series of 6-8 shorter (partly minute) setae all over this extension plus a short proximal stretch. Appendix masculina bilobate, 1.6-2.7 times as long as terminal segment of antennular trunk. Length of antennal scale 4-6 times maximum width; scale clearly reaching beyond antennular trunk. Median segment of mandibular palp with setae on both margins. About evenly rounded hump on the outer face of the distal segment of the maxillula. Carpopropodus of first to eighth thoracic endopods with 2, 2, 3, 3, 3, 3, 3-2, and 2-3 segments, respectively. Basal segment occupies half total length of carpopropodus of endopod 3. Pleopod 1 rod-like to indistinctly bilobate in both sexes. Sympod of pleopod 4 with endite missing or reduced to weak medial hump. Basal segment occupies 56-69\% total length of exopod. Endopod reduced to lobe with $12-18 \%$ sympod length; apically with one long seta and more proximally additional 4-7 shorter, barbed setae. Endopod of uropods 0.6-0.8 times length of exopod. Telson subrectangular, length 1.4-2.0 times maximum width near basis; lateral margins slightly tapering or parallel. Proximal $46-64 \%$ of lateral margins smooth, distal portion of each margin with dense, continuous series of 11-15 acute spines. Terminal margin concave, densely furnished with 15-21 apically blunt laminae.

\section{Descriptive notes}

Adult females of present material with 4.4-6.3 mm $(n=26)$ body length, males 3.4-6.6 mm $(n=38)$. Antennular trunk extends $-5 \%$ up to $+23 \%$ its length beyond (artificially aligned) eyes (Fig. 1A). Antennal scale 1.3-1.8 times trunk. Sympod of antenna produced into spiniform extension on outer distal corner. Thoracic endopod 8 (when stretched) reaching backwards at most to the middle of pleonite 4 and forwards to mandibles; its carpopropodus $83-94 \%$ length of merus or $29-53 \%$ of telson. Pleonites $1-5$ are $0.5-0.7,0.6-0.8,0.6-0.8,0.5-0.7$ or $0.5-0.8$ times as long as pleonite 6 , respectively. Sizes increase from pleopods 1 to 4, while pleopod 5 ranges between pleopods 1 and 2 in both sexes; amplitude of this variation much stronger in males than females. Pleopod 1 (Fig. 1D) stouter compared to remaining pleopods. Pleopods $2-5$ of females and 2, 5 of males are essentially rod-like. Pleopods $1-3$ with a ventrolaterally directed fan of plumose setae in both sexes. Setae forming the fan of pleopod 1 larger compared to those of pleopods 2-5 in females and 2, 3, 5 in males. Male pleopod 4 (Fig. 1F) very long, exopod reaching at most to basal third of telson; its subapical seta up to the apex of telson. Endopod with apical 




Fig. 1. Mysidium gracile (Dana, 1852), off Cabo Frio in Brazil, non-types. A-B. đ̂, $5.6 \mathrm{~mm}$ body length. C, G. $\widehat{\delta}, 5.3 \mathrm{~mm}$. D-F. $\curvearrowright, 5.2 \mathrm{~mm}$. A. Cephalic region, right antennula and setae of antennal scale omitted. B. Mediodistal extension of right antennular trunk, dorsal. C. Third thoracic endopod, caudal. D-E. Pleopods 1 and 3, rostral. F. Pleopod 4, caudal. G. Telson. 
seta 2.2-4.6 times endopod length. Sympod with field of scales on its medial hump, or in analogous position upon missing hump. Scutellum paracaudale triangular with acute apex; upper margin weakly convex, lower margin concave or S-shaped. Uropodal endopod 1.0-1.4 times, exopod 1.3-1.9 times as long as pleonite 6. Exopod extends $0.2-0.4$ times its length beyond endopod, or $0.5-0.7$ times beyond telson; endopod 0.2-0.6 times its length beyond telson. Telson (Fig. 1G) length 0.4-0.6 times uropodal exopod, 0.5-0.7 times endopod and 0.7-0.8 times pleonite 6. Statoliths composed of fluorite. Structure of foregut and nauplioid larvae essentially as in M. triangulare sp. nov. (Fig. 8A-F, N-M).

\section{Distribution and habitat}

Widely distributed, mainly in sublittoral, also in littoral waters of the West Atlantic in the range of $32^{\circ} \mathrm{N}$ to $24^{\circ} \mathrm{S}$ (Bermuda to coast near São Sebastião, Brazil), including the Caribbean (Price \& Heard 2004; Ortiz et al. 2017b). Masses were recorded from the surface zone of a sandy beach in Venezuela (EstevesAstudillo et al. 2017). Distribution mostly euhaline, also found in the metahaline reach of a lagoon by Zoppi de Roa et al. (1989). The species forms swarms close to the bottom in a variety of coral reef habitats (Emery 1968; Brattegard 1969). Swarms may hover near the sea urchin Diadema antillarum Philippi, 1845, where they withdraw to the safety of the interspaces between the spines when threatened (Randall et al. 1964). They may also crowd in the nest caves of pomacentrid fish when a predator approaches (Emery 1968). The swarms disperse during the night and the individuals show homing behaviour by regrouping at the same location in the morning (Twining et al. 2000). Present records from Curaçao, Bonaire, and SE-Brazil; in swarms hovering during the daytime over the sea floor at a depth of 3-35 m, also found between corals.

\section{Mysidium (Mysidium) integrum W.M. Tattersall, 1951}

Fig. 2

Mysidium integrum W.M. Tattersall, 1951: 223-226, fig. 96.

Mysidium integrum - Banner 1954: 447. — Brattegard 1969: 82; 1970: 128; 1973: 50; 1974a: 69; 1974b: 112, table 1; 1975: 112. — Mauchline 1980: 338 (in list). — Băcescu \& Ortiz 1984: 22 (in key). — Modlin 1984: 282; 1987: 115. — Price et al. 1986: table 1; 2002: 46. — Harrison \& Bowman 1987: 678 (in comparison). — Zoppi de Roa et al. 1989: 31. — Escobar Briones \& Soto 1991: table 1. — Schlacher et al. 1992: table 1. — Ariani et al. 1993: table 1. — Wittmann et al. 1993: fig. 3H. Price \& Heard 2004: 155; 2009: 938 (in list). — Sorbe et al. 2007: table I. — Wittmann et al. 2014: fig. 54.27E. — Ortiz et al. 2017a: 113; 2017b: 72. — Ortiz \& Lalana 2018: 81.

non Mysidium integrum — Zoppi de Roa et al. 1989: fig. 3.

\section{Type material}

Not examined.

\section{Other material examined}

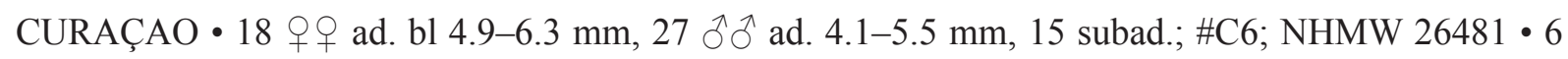
subad. bl 2.8-4.1 mm; \#C7; MINGA MYS 437 • 51 q ㅇ ad. bl 3.8-5.9 mm, 32 ふ઼ ad. bl 4.0-5.1 mm, 5 subad.; \#C9; MINGA MYS $437 \bullet 88$ 우 ad. bl 3.8-5.9 mm, 25 ठิ $\widehat{o}$ ad. bl 3.2-5.2 mm, 20 subad.; \#C10; ZMH K-55261.

SE-BRAZIL • 6 q $q$ ad. bl 4.8-6.0 mm, 33 §ैô ad. bl 4.3-6.1 mm, 6 subad.; \#F13; ZMH K-55265. 


\section{Type locality}

Tropical NW-Atlantic, Cruz Bay, St. John, Virgin Islands (W.M. Tattersall 1951). Coordinates estimated by present authors as $18.3322^{\circ} \mathrm{N}, 64.7967^{\circ} \mathrm{W}$.

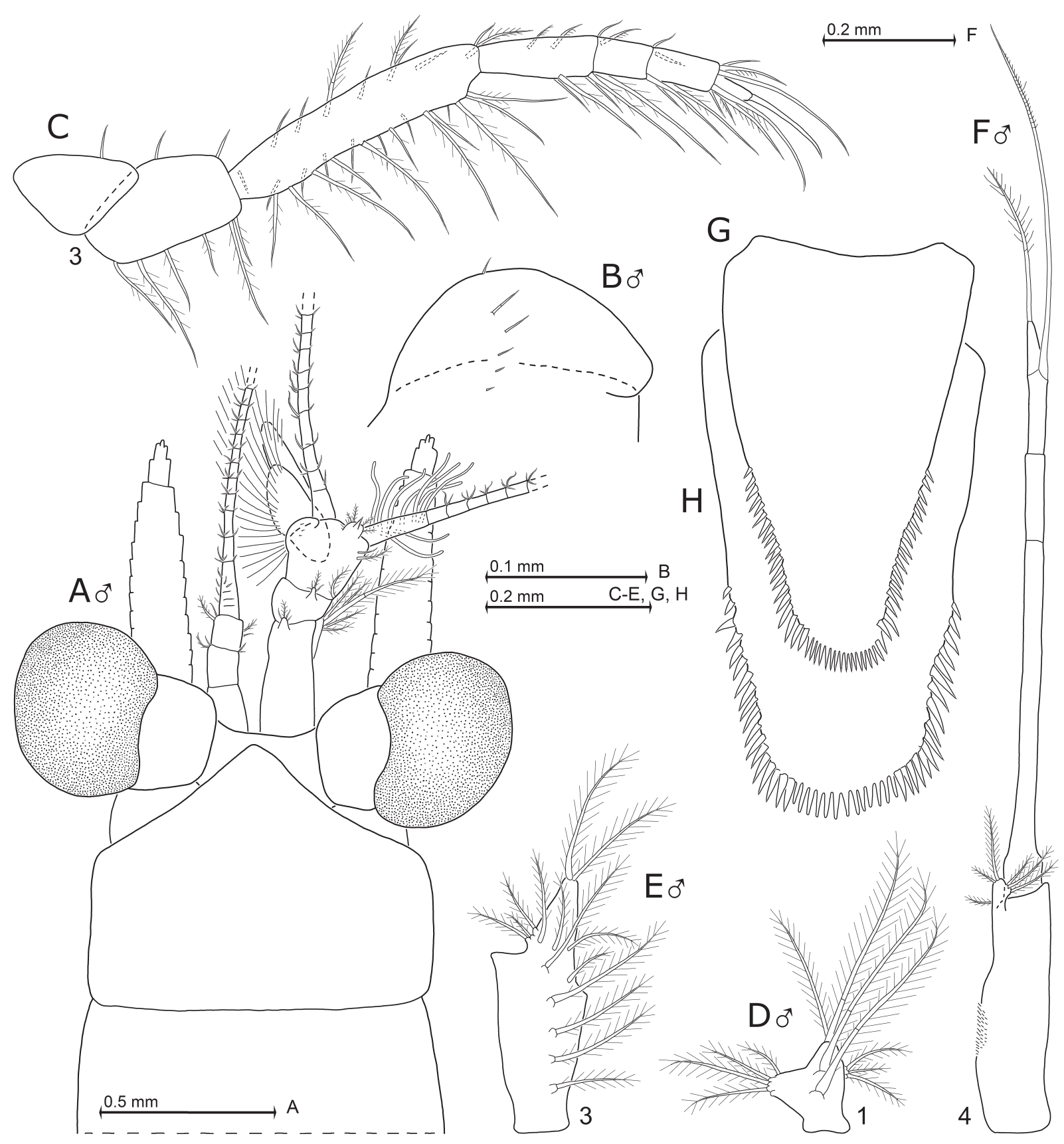

Fig. 2. Mysidium integrum W.M. Tattersall, 1951, from Curaçao (A-G) and off Cabo Frio in Brazil (H), non-types. A. ${ }^{\lambda}, 5.1 \mathrm{~mm}$ body length. B. ${ }^{\lambda}, 5.3 \mathrm{~mm}$. C-G. ${ }^{\lambda}, 4.6 \mathrm{~mm}$. H. ${ }^{\lambda}, 6.8 \mathrm{~mm}$. A. Cephalic region; left antennula and setae of antennal scale omitted. B. Mediodistal extension of right antennular trunk, dorsal view. C. Third thoracic endopod, caudal view. D-E. Pleopods 1 and 3, rostral view. F. Pleopod 4, caudal view. G-H. Telson variants. Sample affiliation: Curaçao \#C3 (A, C-G), \#C9 (B); Brazil \#F13 (H) 


\section{Revised definition}

All features diagnosed above for genus and subgenus Mysidium Dana, 1852. Cornea globose in lateral view; calotte-shaped in dorsal view, with diameter 1.6-2.4 times as long as terminal segment of antennular trunk. Eyestalks smooth. Rostrum broadly triangular, apically bluntly pointed to well rounded, not extending beyond basis of eyestalks. Antero-lateral edges of carapace rounded. Only males with anterior margin of antennular trunk dorsally with rounded, shield-like, mediodistal extension (Fig. 2A-B); longitudinal series of 4-6 setae all over this extension plus a short proximal stretch. The largest seta $0.3-0.5$ times extension length. Appendix masculina bilobate, all along inner margins fringed by large setae; its length 1.1-2.5 times terminal segment of antennular trunk. Length of antennal scale 4-5 times maximum width; scale reaching well beyond antennular trunk. Median segment of mandibular palp with setae on both margins. Weak, about evenly rounded hump on outer face of distal segment of the maxillula. Carpopropodus of first to eighth thoracic endopods with 2, 2, 3, 3, 3, 3-2, $3-2$, and 2-3 segments, respectively. Basal segment occupies half total length of carpopropodus of endopod 3. Pleopod 1 representing a stout, bilobate plate in both sexes. Sympod of male pleopod 4 with endite reduced to weak medial hump or missing. Basal segment of exopod measures 49-63\% total length. Endopod reduced to setose lobe with 11-24\% sympod length; apically with 1-2 setae and more proximally additional 4-6 barbed setae, total of 5-7 setae. Endopod of uropods 0.7 times as long as exopod. Telson spatulate, caudally gradually narrowing; length 1.5-1.8 times maximum width near basis; latero-terminal corners rounded; terminal margin traverse to convex. Proximal 52-62\% of lateral margins smooth, distal portion of each margin with dense, continuous series of 13-25 acute spines. This series extending up to the latero-terminal corner. Terminal margin lined by $12-20$ densely set, acute (Fig. 2G) or blunt (Fig. 2H) laminae. These laminae more slender compared to the neighboring lateroterminal spines.

\section{Descriptive notes}

Adult females of present material with 3.8-6.3 mm ( $\mathrm{n}=163)$ body length, males 3.2-6.1 mm $(\mathrm{n}=117)$. Antennular trunk extends 9-57\% its length beyond (artificially aligned) eyes (Fig. 2A). Antennal scale 1.3-1.5 times as long as trunk. Sympod of antenna produced into spiniform extension on outer distal corner. Thoracic endopod 8 (when stretched) reaching backwards at most to middle of pleonite 4 and forwards to mandibles; its carpopropodus $69-84 \%$ as long as merus or $38-53 \%$ times telson length. Pleonites $1-5$ are $0.6-0.8,0.6-0.7,0.6-0.7,0.5-0.6$ or $0.6-0.7$ times as long as pleonite 6 , respectively. Sizes increase from pleopods 1 to 4 , while pleopod 5 ranges between 1 and 2 in both sexes; amplitude of this variation much stronger in males than females. Pleopod 1 (Fig. 2D) stouter compared to the remaining pleopods. Pleopods $2-5$ of females and 2, 5 of males are essentially rod-like. Pleopods $1-3$ with a ventro-laterally directed fan of plumose setae in both sexes. Setae forming the fan of pleopod 1 are larger compared to those of pleopods 2-5 in females and 2, 3, 5 in males. Male pleopod 4 (Fig. 2F) reaching at most to basal third of telson, its subapical seta up to basal third of uropodal exopod. Sympod with field of scales on its medial hump, or in analogous position upon missing hump. Endopod with its larger apical seta 1.8-3.1 times endopod length. Scutellum paracaudale triangular with acute apex; upper margin convex to concave, lower margin straight to slightly convex or S-shaped. Uropodal endopod 1.1-1.2 times, exopod 1.6-1.8 times as long as pleonite 6. Exopod extends 0.2-0.4 times its length beyond endopod, or 0.6-0.7 times beyond telson; endopod $0.5-0.6$ times its length beyond telson. Telson (Fig. 2G-H) length $0.4-0.5$ times uropodal exopod, $0.5-0.7$ times endopod or $0.7-0.8$ times pleonite 6. Statoliths composed of fluorite. Structure of foregut and nauplioid larvae essentially as in M. triangulare sp. nov. (Fig. 8A-F, M-N).

\section{Distribution and habitat}

Reported from euhaline coastal waters of Bermuda, Bahamas, Caribbean and Gulf of Mexico (Brattegard 1970, 1973; Ortiz et al. 2017b). The present record from the Brazilian coast off Cabo Frio represents 
a strong extension of the known distribution to the south, yielding a total range from $32^{\circ} \mathrm{N}$ to $23^{\circ} \mathrm{S}$ along the coasts of the West Atlantic. According to Zoppi de Roa \& Alonso (1997) these mysids form swarms close to the bottom of diverse coral reef and mangrove habitats, also found among spines of the sea urchin Diadema antillarum. The present data from Curaçao and SE-Brazil were recorded during the daytime at a depth of $0-35 \mathrm{~m}$, on swarms mostly hovering around, between or above rock and coral blocks, also from the entrance area of a cave. Most surprising was sample C9 (Table 1) from the water edge where the mysids showed a striking green body color upon swarming above algae at a depth of only $5 \mathrm{~cm}$.

\section{Mysidium (Mysidium) cubanense Băcescu \& Ortiz, 1984}

Fig. 3

Mysidium cubanense Băcescu \& Ortiz, 1984: 18-20, fig. 2A-K.

Mysidium cubanense - Harrison \& Bowman 1987: 678 (in comparison). — Ortiz \& Lalana 1988: 14 (in list); 1997: 187; 2018: 67. — Băcescu 1991: 3-6. — Escobar-Briones \& Soto 1991: table 1. — Ortiz 2001: 100 (in list) . - Ortiz et al. 2006: 3; 2017a: 113; 2017b: 72-74. — Petrescu \& Wittmann 2009: 54. — Price \& Heard 2009: 938 (in list).

Mysidium cubanensis - Harrison \& Bowman 1987: 674, 678 (gender inconsistency).

\section{Type material examined}

\section{Holotype}

CUBA $\cdot$ adult ${ }^{\lambda}$, partly dissected, bl $4.5 \mathrm{~mm}$; in front of Marine Research Center, Habana, at the entrance of a small underwater cave; $23.1334^{\circ} \mathrm{N}, 82.3334^{\circ} \mathrm{W} ; 13 \mathrm{~m}$; 13 May 1983; Manolo Ortiz leg.; Mihai Băcescu det.; MINGA 49346/601a.

\section{Other material examined}

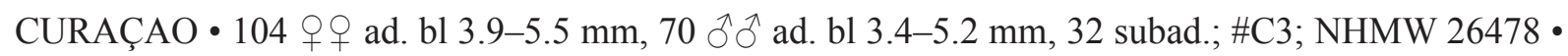
2 우우 ad. bl 3.6-4.1 mm; \#C4; ZMH K-55257 - 383 우 ad. bl 4.2-5.8 mm, 96 §ోळ ad. bl 3.1-5.9 mm,

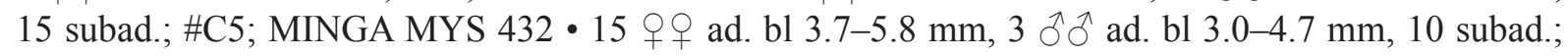
\#C8; ZMH K-55259.

BONAIRE • 20 우 ad. bl 3.2-4.4 mm, 5 ô 0 ad. bl 3.3-4.0 mm, 10 subad.; \#B11; MINGA MYS 438.

\section{Type locality}

Miramar, La Habana, Cuba (Băcescu \& Ortiz 1984), 23.1334 N, 82.3334 W.

\section{Revised definition}

All features diagnosed above for genus and subgenus Mysidium Dana, 1852. Cornea large, globose to ellipsoidal in lateral view, calotte-shaped to crescent-like in dorsal view, with 'diameter' 2.6-4.1 times as long as terminal segment of antennular trunk. Eyestalks smooth. Rostrum (sub)triangular, apically bluntly pointed to well rounded, not extending beyond basis of eyestalks. Antero-lateral edges of carapace rounded. Only males with anterior margin of antennular trunk dorsally with rounded, shield-like, mediodistal extension (Fig. 3A-B); longitudinal series of 4-6 setae extending all over this extension plus a short proximal stretch. The largest seta $0.2-0.4$ times extension length. Appendix masculina bilobate, all along inner margins fringed by large setae; its length 1.1-2.3 times terminal segment of antennular trunk. Length of antennal scale 4-6 times maximum width; scale reaching beyond antennular trunk. Median segment of mandibular palp with setae on both margins. Large, about evenly rounded hump on outer face of distal segment of maxillula. Carpopropodus with two segments 
in thoracic endopods 1-2, 8, versus three segments in endopods 3-7. Basal segment occupies half total length of carpopropodus of endopod 3. Pleopod 1 bilobate in both sexes. Sympod of male pleopod 4 with endite reduced to weak medial hump or missing. Basal segment of exopod occupies $54-61 \%$ total length. Endopod reduced to lobe with 14-18\% sympod length; apically with one long seta and more proximally additional 4-6 shorter, barbed setae. Endopod of uropods $0.6-0.8$ times as long as exopod. Telson subrectangular to trapezoid; length 1.6-2.1 times maximum width near basis; its lateral margins slightly concave to almost straight; latero-terminal corners rounded; terminal margin traverse to convex.

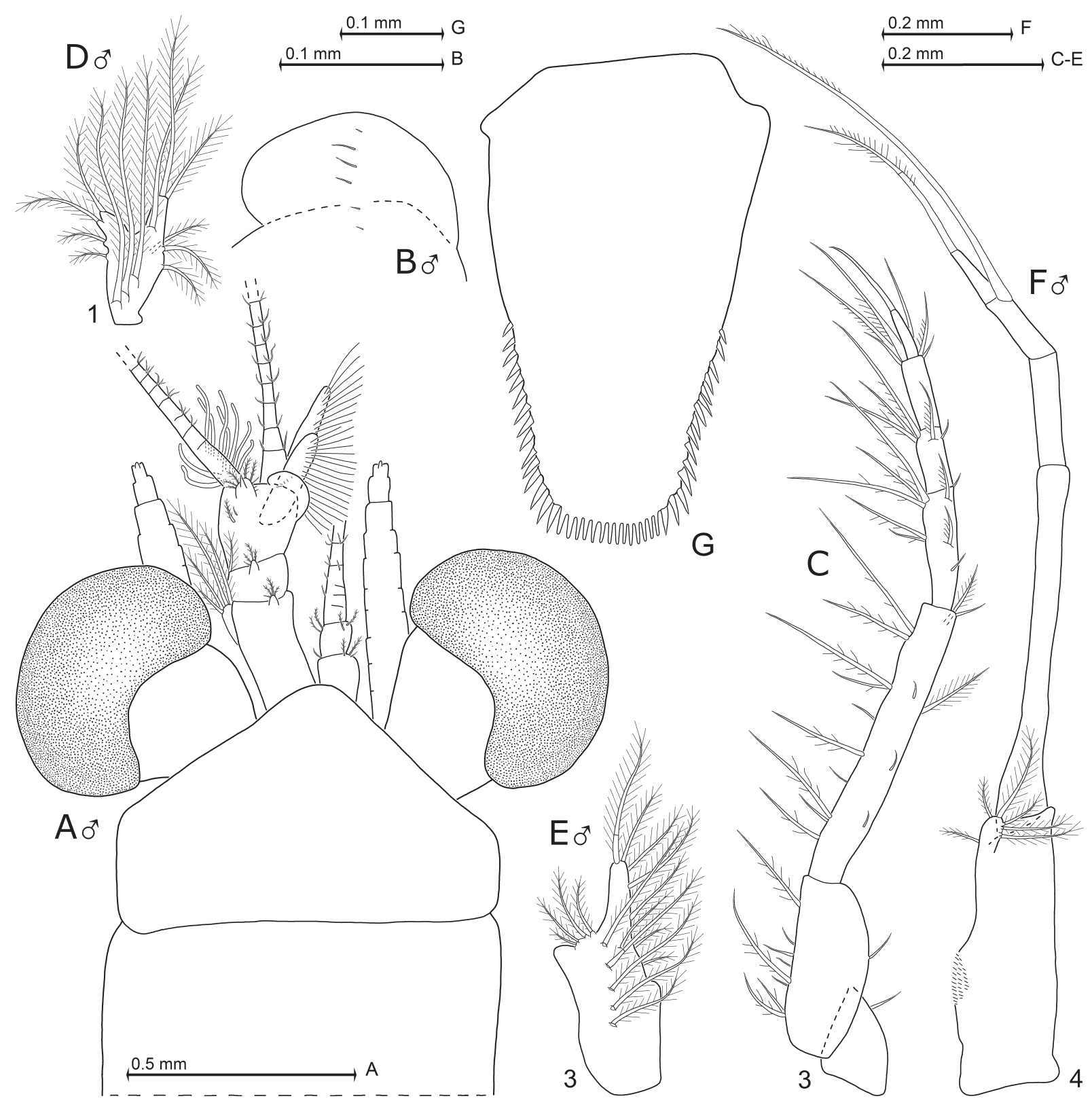

Fig. 3. Mysidium cubanense Băcescu \& Ortiz, 1984, from Cuba (A), Curaçao (B-F) and Bonaire (G). A. Holotype, $\widehat{\jmath}, 5.1 \mathrm{~mm}$ body length. B-F. Non-type, $\widehat{\jmath}, 5.0 \mathrm{~mm}$. G. Non-type, $\widehat{\jmath}, 4.0 \mathrm{~mm}$. A. Cephalic region, right antennula and setae of antennal scale omitted. B. Mediodistal extension of left antennular trunk, dorsal view. C. Third thoracic endopod, rostral view. D-E. Pleopods 1 and 3, rostral view. F. Pleopod 4, caudal view. G. Telson. Sample affiliation: Cuba - type locality (A); Curaçao \#C3 (B-F); Bonaire \#B11 (G). 
Proximal $48-73 \%$ of lateral margins smooth, distal portion of each margin with dense, continuous series of 7-16 acute spines. This series extending up to the rounded, latero-terminal corner. Terminal margin lined by $12-20$ densely set, apically blunt or weakly pointed laminae.

\section{Descriptive notes}

Adult females of present material with $3.2-5.8 \mathrm{~mm}(\mathrm{n}=524)$ body length, males $3.0-5.9 \mathrm{~mm}(\mathrm{n}=$ 174). Antennular trunk extends $0-20 \%$ its length beyond (artificially aligned) eyes (Fig. 3A). Antennal scale 1.1-1.4 times as long as trunk. Sympod of antenna produced into spiniform extension on outer distal corner. Thoracic endopod 8 (when stretched) reaching backwards at most to end of pleonite 4 and forwards to mandibles; its carpopropodus $60-83 \%$ as long as merus or $26-45 \%$ times as long as telson. Pleonites $1-5$ are $0.5-0.6,0.5-0.6,0.5-0.7,0.5-0.7$ or $0.5-0.7$ times as long as pleonite 6 , respectively. Sizes increase from pleopods 1 to 4, while pleopod 5 ranges between 1 and 2 in both sexes; amplitude of this variation much stronger in males than females. Pleopods 1 and 3 stouter compared to remaining pleopods. Pleopods $2-5$ of females and 2, 5 of males are essentially rod-like. Pleopods $1-3$ with a ventrolaterally directed fan of plumose setae in both sexes. Setae forming the fan of pleopod 1 (Fig. 3D) larger than those of pleopods 2-5 in females and 2, 3, 5 in males. Male pleopod 4 (Fig. 3F) reaching at most to distal $4 / 5$ of pleonite 6; its subapical seta up to end of telson. Endopod with apical seta 1.4-2.8 times endopod length. Sympod with field of scales on its weak medial hump, or in analogous position upon missing hump. Scutellum paracaudale triangular with acute apex; upper margin convex or S-shaped, lower margin straight to slightly convex or S-shaped. Uropodal endopod 1.1 times, exopod 1.4-1.6 times as long as pleonite 6. Exopod extends $0.3-0.4$ times its length beyond endopod, or $0.4-0.6$ times its length beyond telson; endopod 0.3-0.4 times its length beyond telson. Telson (Fig. 3G) length 0.50.6 times as long as uropodal exopod, $0.6-0.7$ times endopod and $0.7-0.8$ times pleonite 6 . Statoliths composed of fluorite. Structure of foregut and nauplioid larvae essentially as in $M$. triangulare sp. nov. (Fig. 8A-F, M-N).

\section{Distribution}

Euhaline coastal waters in the Gulf of Mexico, Bahamas, Cuba, Jamaica, Caribbean (Ortiz et al. 2017b). The present records are the first for Bonaire and Curaçao, thus extending the known latitudinal range southward to $12-23^{\circ} \mathrm{N}$. Most samples are from swarms between corals.

\section{Mysidium (Mysidium) rubroculatum Băcescu \& Ortiz, 1984}

Fig. 4

Mysidium rubroculatum Băcescu \& Ortiz, 1984: 20-21, fig. 1F-P.

Mysidium rubroculatum - Harrison \& Bowman 1987: 674 (in comparison). - Ortiz \& Lalana 1988: 14 (in list); 2018: 73. — Escobar-Briones \& Soto 1991: table 1. — Ortiz 2001: 100 (in list). Petrescu \& Wittmann 2009: 64. — Price \& Heard 2009: 939 (in list). — Ortiz et al. 2017a: 113; 2017b: 79-81.

\section{Type material examined}

\section{Paratypes}

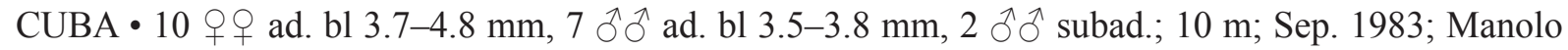
Ortiz leg.; Mihai Băcescu det.; MINGA 49342/600.

\section{Type locality}

Miramar, La Habana, Cuba (Băcescu \& Ortiz 1984), 23.1334 N, 82.3334 W. 


\section{Revised definition}

All features diagnosed above for genus and subgenus Mysidium Dana, 1852. Cornea globose in lateral view, calotte-shaped in dorsal view, with diameter 1.9-2.9 times as long as terminal segment of antennular trunk. Eyestalks smooth. Rostrum (sub)triangular, with rounded to acute apex, rostrum not extending beyond basis of eyestalks. Antero-lateral edges of carapace rounded. Only males with anterior margin of antennular trunk dorsally with rounded, shield-like, mediodistal extension (Fig. 4AB) bearing a longitudinal series of 4-5 setae. The largest seta $0.1-0.3$ times extension length. Appendix masculina bilobate, along inner margins fringed by large setae; its length 1.3-2.0 times terminal segment

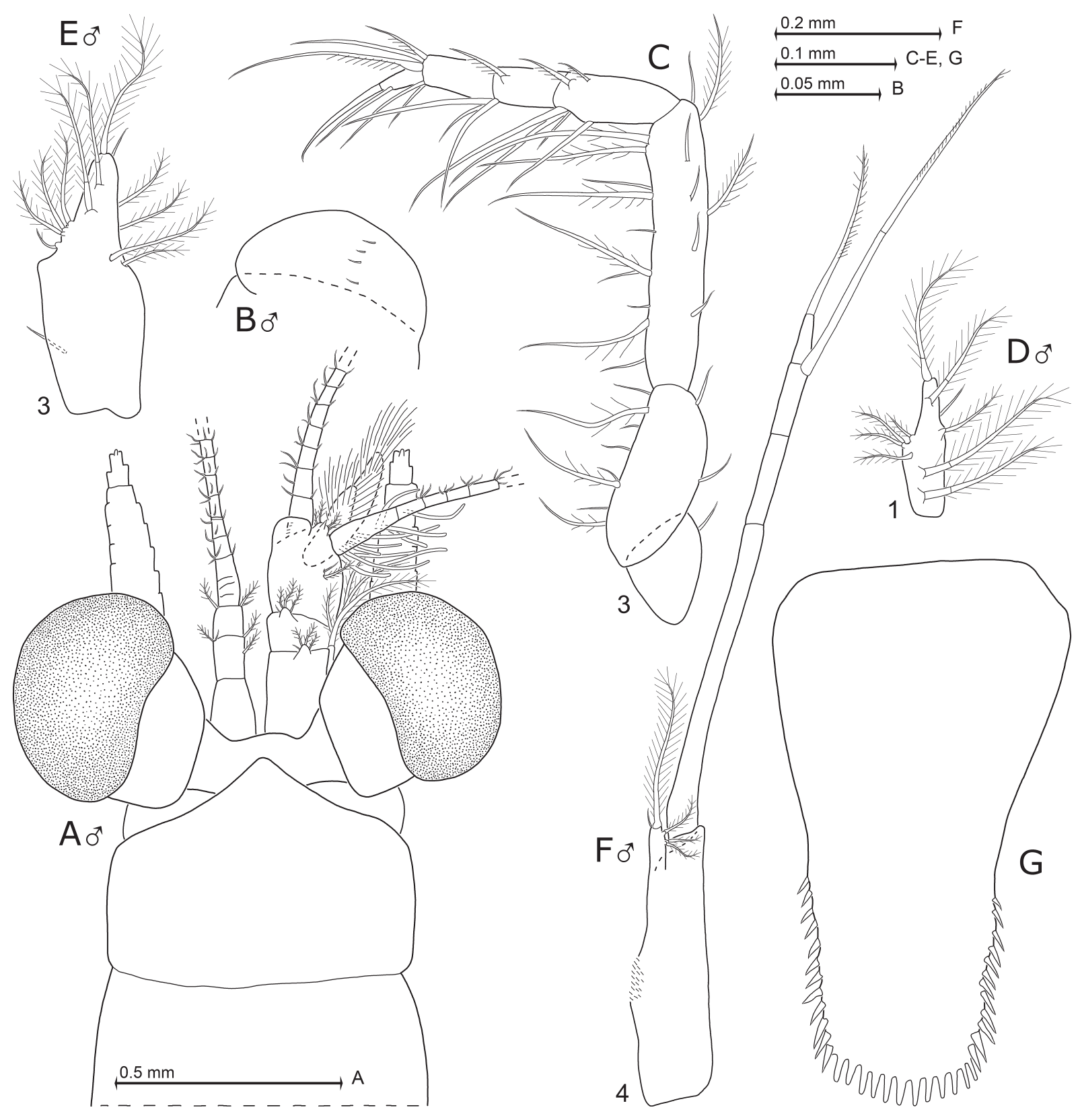

Fig. 4. Mysidium rubroculatum Băcescu \& Ortiz, 1984, from Cuba, paratypes. A. Ô, 3.6 mm body length. B-G. 0 , $3.8 \mathrm{~mm}$. A. Cephalic region, left antennula and setae of antennal scale omitted. B. Mediodistal extension of left antennular trunk, dorsal view. C. Third thoracic endopod, rostral view. D-E. Pleopods 1 and 3, rostral view. F. Pleopod 4, caudal view. G. Telson. 
of antennular trunk. Length of antennal scale 4-5 times maximum width; scale reaching well beyond antennular trunk. Median segment of mandibular palp with setae on both margins. Large, moderately unevenly rounded hump on outer face of distal segment of the maxillula. Carpopropodus with two segments in thoracic endopods 1-2, 8, versus three segments in endopods 3-7. Basal segment occupies half total length of carpopropodus of endopod 3. Pleopod 1 minute, rod-like (Fig. 4D) in both sexes, not considering the weak median widening at its vestigial endopodal portion. Sympod of male pleopod 4 with endite reduced to a weak medial hump or missing. Exopod with basal segment occupying 52-63\% total length. Endopod reduced to lobe with $13-17 \%$ sympod length; apically with a long seta plus a minute seta and more proximally $2-4$ additional small barbed setae. Endopod of uropods $0.7-0.8$ times as long as exopod. Telson subrectangular, caudally narrowing by $30-54 \%$; length $1.5-1.8$ times maximum width near basis; lateral margins slightly concave to almost straight; latero-terminal corners rounded; terminal margin slightly convex to traverse. Proximal $50-60 \%$ of lateral margins smooth, distal portion of each margin with dense, continuous series of 8-12 acute spines. This series extending up to the rounded, latero-terminal corner. Terminal margin lined by 11-18 strong, apically blunt laminae; these last stouter compared to the neighboring latero-terminal spines.

\section{Descriptive notes}

Antennular trunk extends $0-30 \%$ its length beyond (artificially aligned) eyes (Fig. 4A). First to third segments occupy $40-43 \%, 16-20 \%$ or $39-44 \%$ total length, respectively. Appendix masculina $0.5-0.7$ times total trunk length. Antennal scale 1.2-1.4 times antennular trunk, its terminal segment occupying $12-19 \%$ total length and bearing five plumose setae. Sympod of antenna produced into spiniform extension on outer distal corner. Thoracic endopod 8 (when stretched) reaching backwards at most to the middle of pleonite 4 and forwards to maxillula; its carpopropodus $62-69 \%$ as long as merus or $0.3-0.5$ times telson length. Pleonites $1-5$ are $0.7-0.8,0.6-0.8,0.6-0.8,0.5-0.6$ or $0.5-0.6$ times the length of pleonite 6 , respectively. Both sexes with pleopods $1-3$ bearing a ventro-laterally directed fan of plumose setae. Setae of pleopod 1 (Fig. 4D) on average longer than those of pleopods 2, 3, 5 (Fig. 4E). Male pleopod 4 (Fig. 4F) reaching at most to middle of telson; its subapical seta up to $2 / 3$ as long as endopod of uropod. Endopod of male pleopod 4 with its apical seta 2.1-3.6 times endopod length. Sympod with field of scales on its medial hump, or in analogous position upon missing hump. Scutellum paracaudale triangular with acute apex; upper and lower margins weakly convex to concave. Uropodal endopod 1.0-1.5 times, exopod 1.3-1.8 times as long as pleonite 6. Exopod extends 0.2-0.3 times its length beyond endopod, or $0.5-0.7$ times beyond telson; endopod $0.4-0.7$ times its length beyond telson. Telson (Fig. 4G) 0.4-0.5 times as long as exopod of uropods, 0.4-0.6 times endopod or 0.7-0.8 times pleonite 6. Statoliths composed of fluorite. Structure of foregut and nauplioid larvae essentially as in M. triangulare sp. nov. (Fig. 8A-F, M-N).

\section{Distribution}

Marine coastal waters of the Gulf of Mexico, Cuba (Ortiz et al. 2017b), 22-23 N.

Mysidium (Mysidium) triangulare Wittmann sp. nov. urn:1sid:zoobank.org:act:B0EB7822-4D13-4D05-8C40-2A7F01297301

Figs 5-8

\section{Etymology}

The species name is a Latin adjective with neutral ending, referring to the triangular terminal portion of the telson.

\section{Type material examined}

Holotype (by present designation)

CURAÇAO - O ad. bl $5.2 \mathrm{~mm}$; sublittoral marine waters of Curaçao, Playa Lagun; $12.3181^{\circ} \mathrm{N}$, 69.1511 S. \#C8; NHMW 26487. 
Paratypes (by present designation)

CURAÇAO • 57 के $\hat{\text { a }}$ ad. bl $3.8-5.7 \mathrm{~mm}, 44$ 우 ad. bl $4.8-5.9 \mathrm{~mm}, 8$ subad.; same locality data as for holotype; \#C8; MINGA MYS 436, NHMW 26488, ZMH K-55260.

\section{Other material examined}

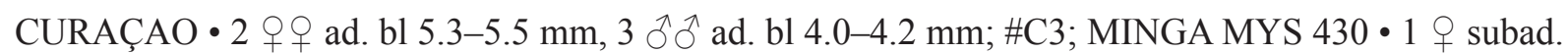
bl $3.5 \mathrm{~mm}$; associated with swarm of M. integrum freely swimming in the entrance area of cave; \#C10.

\section{Definition}

All features diagnosed above for genus and subgenus Mysidium Dana, 1852. Cornea globose in lateral view; calotte-shaped in dorsal view, with diameter 1.7-2.5 times as long as terminal segment of antennular trunk. Eyestalks smooth. Rostrum triangular, apically pointed to well rounded, not extending beyond basis of eyestalks. Antero-lateral edges of carapace rounded. Only males with anterior margin of antennular trunk dorsally with rounded, shield-like, mediodistal extension (Fig. 5A-B); longitudinal series of 6-10 setae extending all over this extension plus a short proximal stretch. The largest seta 0.1-0.3 times extension length. Appendix masculina bilobate, densely setose; its length 1.5-2.0 times terminal segment of antennular trunk. Length of antennal scale 5-7 times maximum width, scale reaching far beyond antennular trunk. Median segment of mandibular palp with setae on both margins. Almost evenly rounded hump on outer face of distal segment of maxillula. Carpopropodus two-segmented in thoracic endopods $1-2,8$, or three-segmented in endopods 3-7, except that endopods 6,7 may be twosegmented in some females. Basal segment occupies 0.4-0.5 times total length of carpopropodus of endopod 3. Pleopod 1 representing a stout, bilobate plate in both sexes. Sympod of male pleopod 4 with endite reduced to a weak medial hump or missing. Exopod with basal segment occupying 56-63\% total length. Endopod reduced to lobe with 10-16\% sympod length; lobe apically with one long, barbed seta and more proximally with additional 4-6 shorter, barbed setae. Endopod of uropods 0.6-0.8 times as long as exopod. Telson spatulate, length 1.9-2.1 times maximum width near basis; median portion with concave lateral margins, terminal portion triangular with rounded tip. Proximal 52-64\% of lateral margins smooth; distal portion of each margin with continuous series of 5-11 acute spines, this series extending up to the corner with the triangular apical portion. Margin of the triangular portion densely furnished with a total of 21-24 strong, apically blunt laminae.

\section{Description}

Body SIZE. Adult females 4.8-5.9 mm $(n=46)$, males 3.8-5.7 mm $(n=61)$.

Antennal appendages (Fig. 5A-B, F-G). Antennular trunk extends $10-50 \%$ its length beyond (artificially aligned) eyes. First to third segments occupy $46-57 \%, 15-18 \%$ or $28-36 \%$ total trunk length, respectively. Trunk dorsally with forward directed small, setose lobes near terminal margin of each segment: two lobes from basal, one from median, and one from terminal segment (not counting the mediodistal extension of anterior margin in males). Appendix masculina 0.4-0.5 times total trunk length, antennal scale 1.1-1.5 times trunk. Sympod of antenna produced into spiniform extension on outer distal corner. Antennal scale with terminal segment occupying $13-24 \%$ total length and bearing five plumose setae.

Mouth ParTs (Figs 5H, J, 6A-C). Mandibular palp without spines; terminal segment with strong, modified, bent seta at apex, and barbed setae along inner and outer margins. Median segment of palp with angular, medially directed dilatation, both its margins setose. Proximal segment normal, with smooth margins. Distal segment of maxillula terminally with strong spines, subterminally with one barbed seta; tip of endite of maxillula with apically modified setae (armed with stiff barbs) plus several shorter setae with normal, fine barbs. Maxilla with well-developed exopod, moderately large, two-segmented palp, 


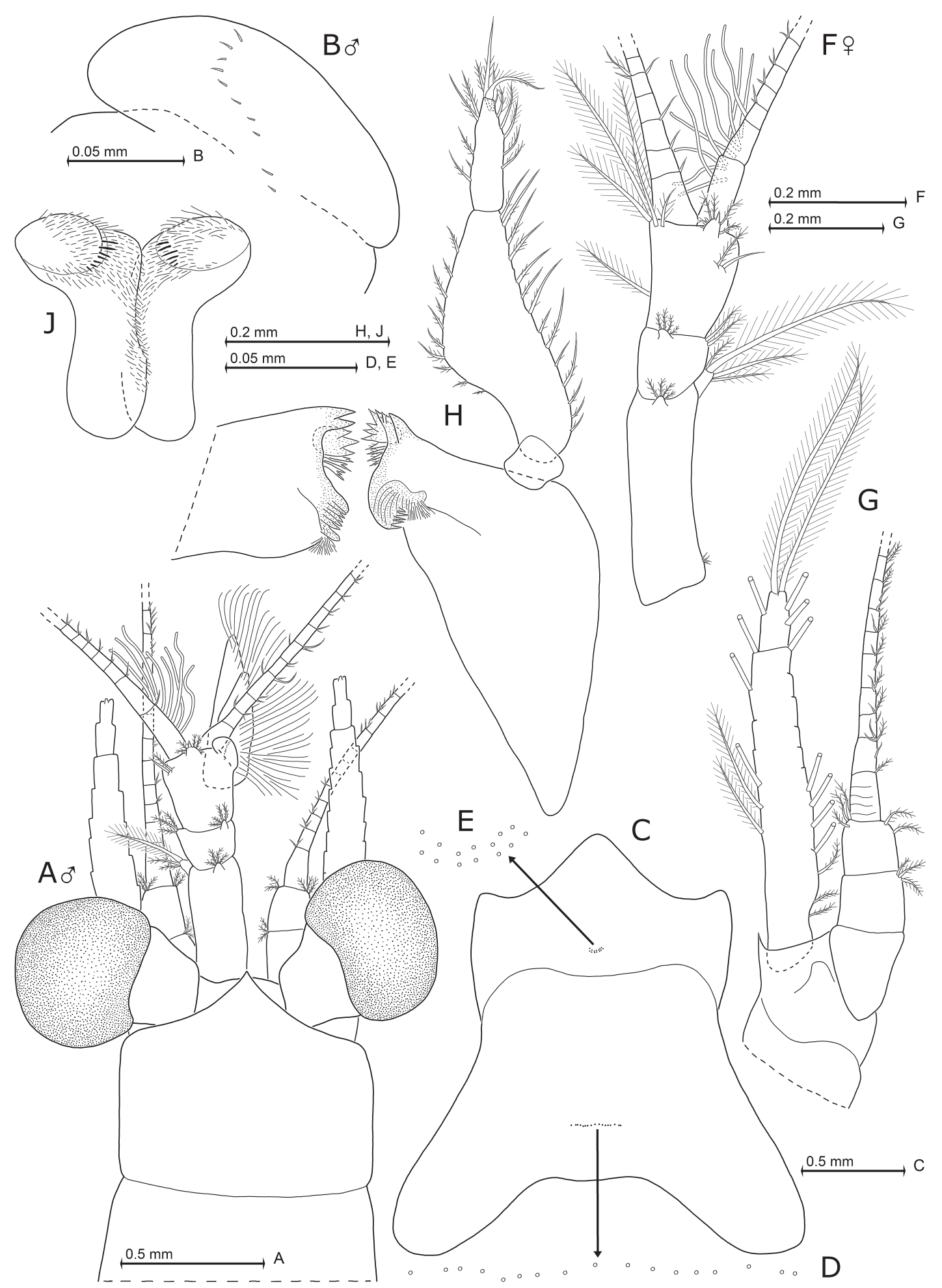

Fig. 5. Mysidium triangulare Wittmann sp. nov., from Curaçao, holotype (A) and paratypes (B-J). A. $\overbrace{}^{\lambda}$,

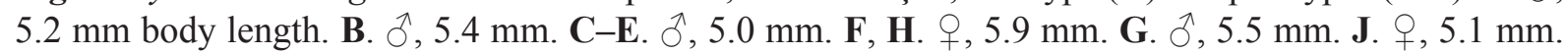
A. Cephalic region; right antennula and setae of antennal scale omitted. B. Mediodistal extension of left antennular trunk, dorsal. C. Carapace expanded on slide. D-E. Details of panel (C) showing cardial (D) and cervical (E) pore groups, pore diameters not to scale. F. Right antennula of female, dorsal view. G. Right antenna, ventral view. H. Right mandible with left masticatory process, rostral view. J. Labium, rostral view. 


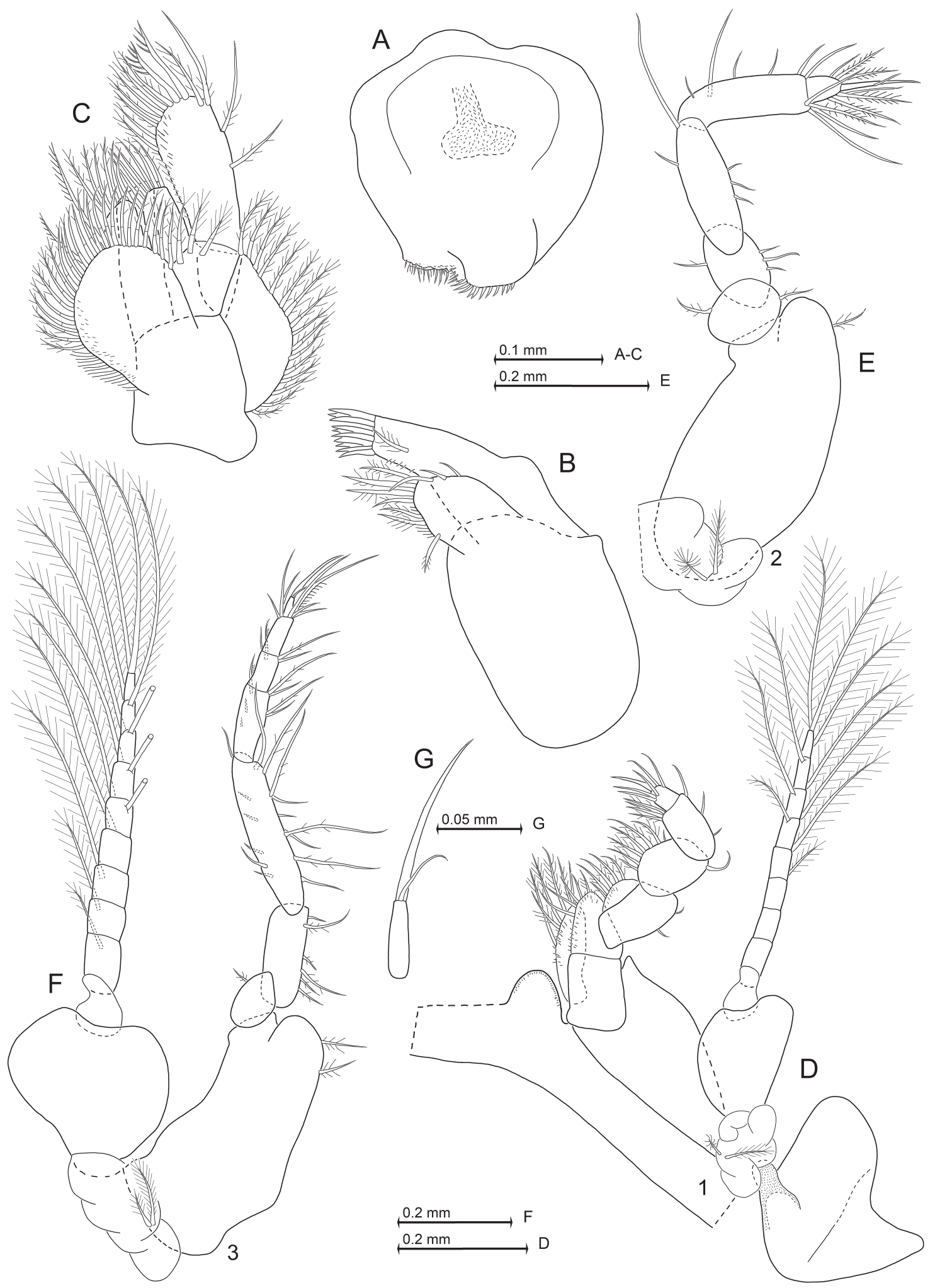

Fig. 6. Mysidium triangulare Wittmann sp. nov., from Curaçao, paratypes. A. $९, 5.1 \mathrm{~mm}$ body length.


view. C. Maxilla, rostral view. D. First thoracopod (caudal view) with part of sternite 1 (ventral view). E. Second thoracic sympod with endopod, caudal view. F. Third thoracopod, caudal view. G. Detail of panel (F) showing dactylus with nail. 
and three apically setose endites. Exopod with maximum width in median portions; its outer margin all along with series of plumose setae. Basal segment of palp with three barbed setae. Apical segment about two times as long as basal segment. Length of apical segment 2.0-2.5 times maximum width, densely setose on terminal margin but lined by small hairs along more than basal half of inner margin. Apex of palp with two strong, modified setae bearing strong, spine-like barbs along distal third of their inner margin.

Foregut (Fig. 8A-F). Essentially as in M. antillarum sp. nov. (Fig. 11A-E). As main differences from that species, $M$. triangulare sp. nov. shows less strongly serrated, apically pronged, large spines: on each lateral half there are two spines (Fig. 8E) on posterior part of lateralia; and a longer one (Fig. 8F) on dorso-lateral infolding; the latter inserting in more median position than in M. antillarum sp. nov.

Thorax of both sexes (Figs 5C-D, 6D-G, 7A-C). Carapace (Fig. 5C-E) posteriorly emarginate, with well-rounded latero-terminal lobes; cervical sulcus strong; roughly V-shaped group of 11-14 pores (Fig. 5E) in front of cervical sulcus, transverse linear series of 13-18 pores (Fig. 5D) in cardial position (above heart). Sternites smooth; a plumose seta accompanied by a shorter barbed seta on the joint between each sternite and the corresponding thoracopods (Fig. 6D). Sizes of endopods and exopods increase from thoracopod 1 to 4 or 5 and decrease from 5 to 8 . Basal plate of exopods 1-7 with large, well rounded latero-distal expansion (Figs 6D, F, 7A-B). Flagellum 8-segmented in exopod 1 versus 9-segmented in exopods 2-7. First endopod (Fig. 6D) with well developed, setose endites from basis, ischium, merus. First thoracic epipod bilobate, with smooth margins, without seta. Endopods 1-2 with large dactylus and strong claw (Fig. 6D-E). Dactylus of thoracic endopod 2 with 3-6 modified and several smooth setae, no spine-like setae; modified setae each with two dense rows of strong, acute barbs along their median to subterminal portions. Endopods 3-7 with less stout, well developed dactylus bearing a long, needle-like claw (Fig. 6G); endopod 8 with seta-like claw (Fig. 7C). Endopod 8 (when stretched) reaching backwards at most to end of pleonite 3 and forwards to maxillula; its carpopropodus measures $0.4-0.5$ times telson length.

Thoracopods of Females (Figs 7A, 8G). Basal plate of exopod 8 with short to indistinct latero-distal expansion; its flagellum only 8 -segmented. Oostegites of thoracopods 7-8 densely fringed with setae, together forming a large brood chamber. Thoracopod 6 (Fig. 7A) with rudimentary oostegite bearing 1-2 long setae at apex. These setae spinulose at least along their apical third. More such setae present in proximal portions of oostegite from thoracopod 7 (Fig. 8G).

Thoracopods of MALeS AND PENIS (Fig. 7B-C). Basal plate of exopod 8 with yet distinct latero-distal expansion; its flagellum 9-segmented. Penes pear-shaped, apically widening; $0.9-1.0$ times as long as merus of endopod 8 . Penes apically bilobate, with row of 4-5 smooth, bent setae flanking the ejaculatory opening. Two additional, smaller, straight setae subapically on margin opposite to bent setae.

Pleon (Figs 7D-M, 8H-L). Pleonites $1-5$ are $0.6-0.7,0.7-0.8,0.7-0.9,0.8-0.9$ or $0.7-0.9$ times as long as pleonite 6 , respectively. Scutellum paracaudale (Fig. $8 \mathrm{H}, \mathrm{J}$ ) triangular, apically pointed to narrowly rounded; margins weakly concave to convex. Uropodal endopod (Fig. 8K) 1.0-1.3 times, exopod 1.41.7 times as long as pleonite 6. Length of exopod 7-9 times maximum width. Exopod extends 0.2-0.3 times its length beyond endopod or 0.5-0.6 times beyond telson; endopod 0.3-0.5 times its length beyond telson. Telson (Fig. 8L) $0.5-0.6$ times as long as exopod of uropods, $0.7-0.8$ times endopod or $0.8-0.9$ times pleonite 6 .

Pleopods of Females (Fig. 7D-G). Pleopods 1-5 subequal in length. Pleopods 1-2 reduced to small bilobate plates, pleopods 3-5 to small, setose rods. Pleopods 1-4 with a ventro-laterally directed fan of plumose setae. Pleopod 1 with clearly the largest setae, although not as large as in males. 


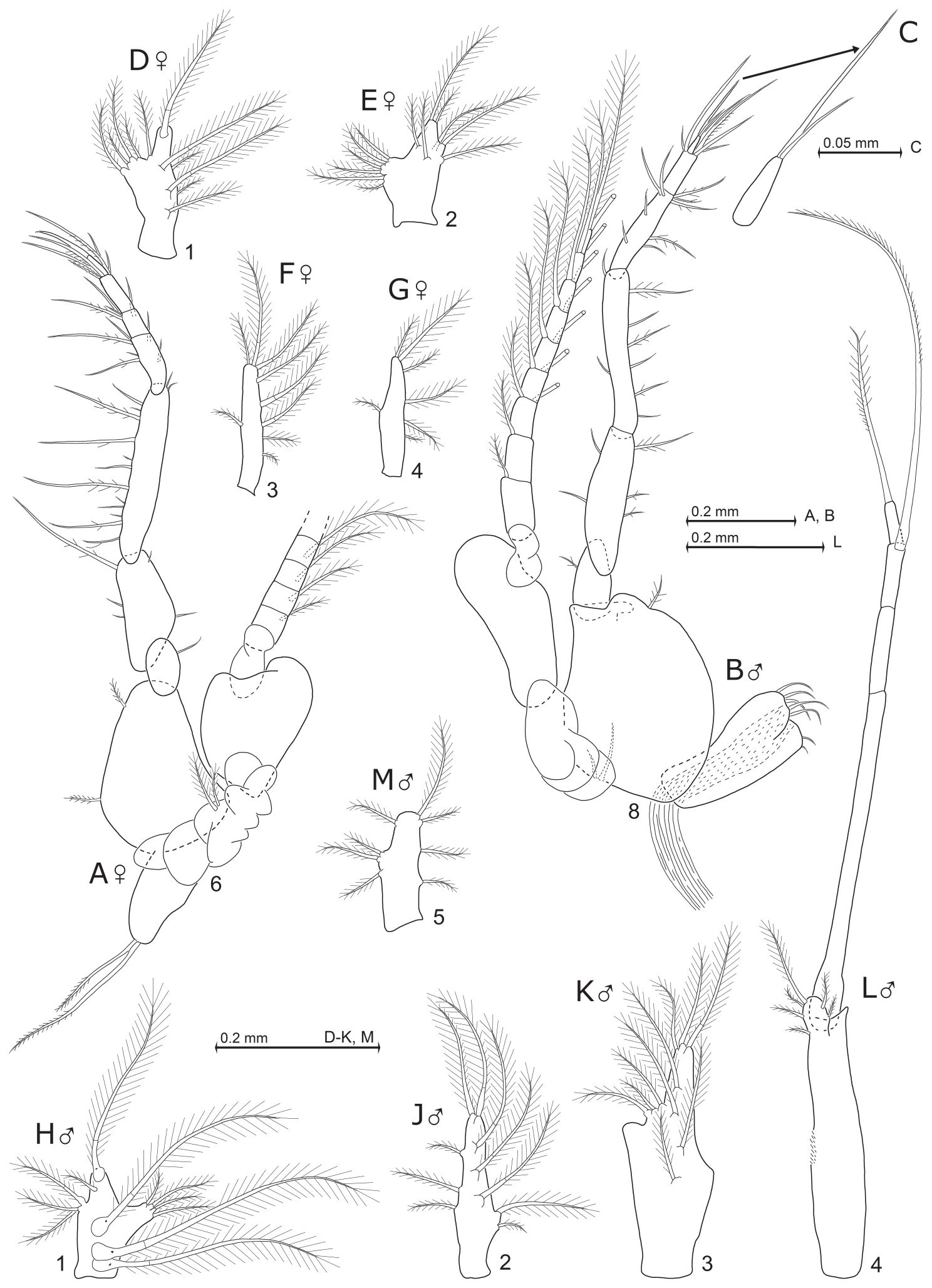

Fig. 7. Mysidium triangulare Wittmann sp. nov., from Curaçao, paratypes. A, D. $\uparrow, 5.4 \mathrm{~mm}$ body length. B-C, K-L. ô, $5.5 \mathrm{~mm}$. E-G.,$+ 5.1 \mathrm{~mm}$. H, J, M. $\delta 5.4 \mathrm{~mm}$. A. Sixth thoracopod with rudimentary oostegite, caudal view. B. Eighth thoracopod with penis, rostral view. C. Detail of panel (B) showing dactylus with nail. D-G. Series of female pleopods 1-4, rostral view. H-K, M. Series of male pleopods 1-3, 5, rostral view. L. Male pleopod 4, caudal view. 

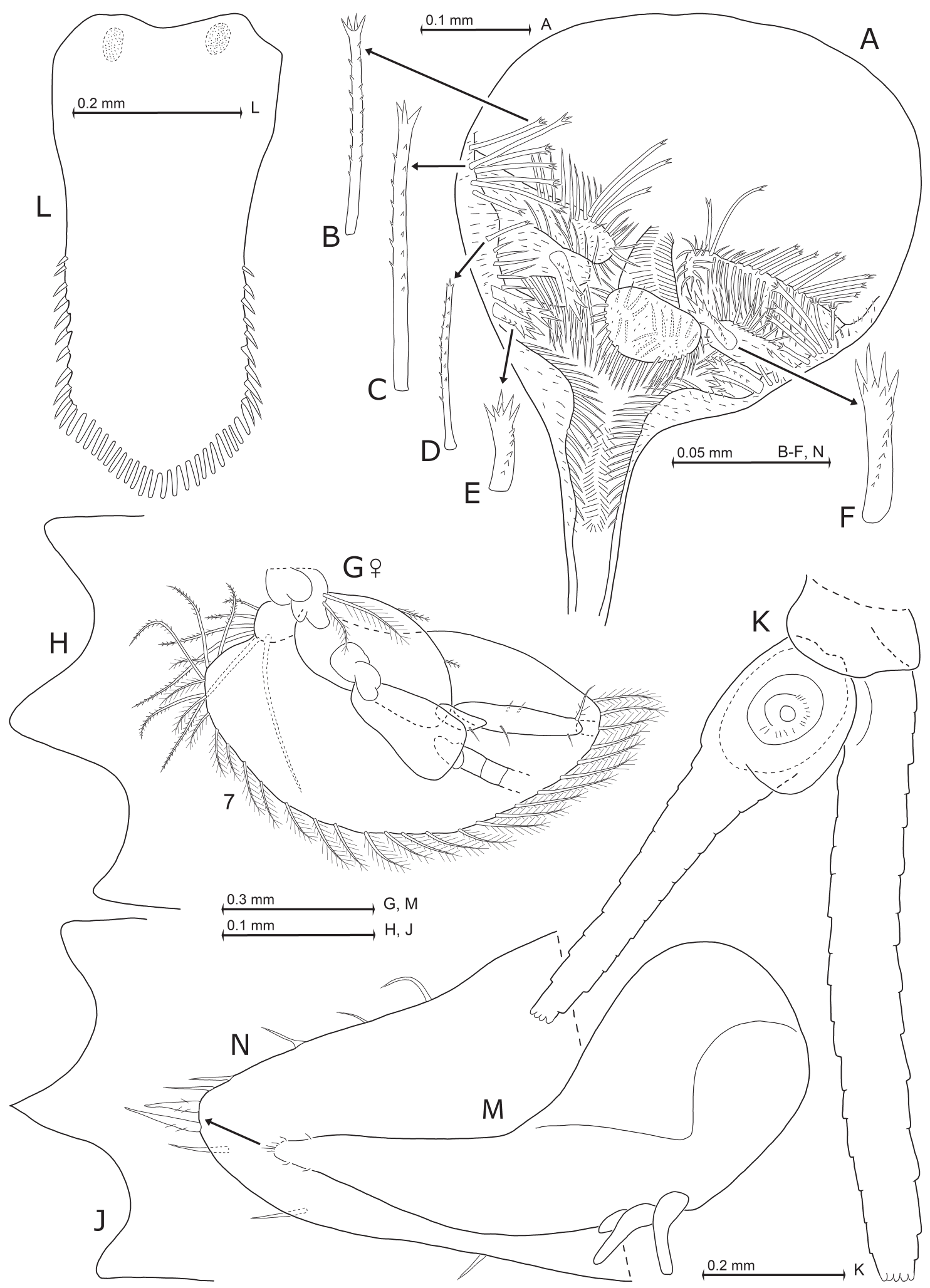

Fig. 8. Mysidium triangulare Wittmann sp. nov., from Curaçao, paratypes. A-F. $९, 5.9 \mathrm{~mm}$ body length. G, J., , $5.1 \mathrm{~mm}$. H, K-L. $\widehat{\jmath}, 5.5 \mathrm{~mm}$. A. Foregut; dorsal wall omitted. B-F. Details of panel (A) showing modified spines. G. Basal half of thoracopod 7 with right oostegite, lateral view. H, J. Variants of scutellum paracaudale, lateral view. K. Uropods, ventral view; setae omitted. L. Telson. M. Nauplioid larva at substage N2, lateral view. N. Detail showing tip of abdomen in another nauplioid specimen. 
Pleopods of Males (Fig. 7H-M). Length increases from pleopod 1 to 4 . Pleopod 5 is about the same length as pleopod 1, but less stout. Pleopods 1-3 with a ventro-laterally directed fan of plumose setae; pleopod 1 with the largest setae of that kind. Fourth pleopod reaching to terminal $50-80 \%$ of pleonite 6 ; its subapical seta reaching up to apex of telson. Its four-segmented exopod with basal segment longest, second segment longer than third, third segment longer than fourth. Subterminal segment of exopod with a very long seta bearing dense series of minute bristles along its distal half; short terminal segment with comparatively large but shorter seta at tip, this seta with characteristic set of barbs (Fig. 7L) along its distal half. Endopod with apical seta 2.0-2.8 times endopod length. Sympod with field of scales on its medial widening, or in analogous position upon missing widening.

Statoliths. Composed of fluorite; shape ellipsoidal to spherical in dorsal view (Fig. 8K); discoidal in lateral view, maximum diameter 89-107 $\mu \mathrm{m}$, thickness $45-54 \mu \mathrm{m}$, measured in 10 adults. Tegmen moderately, though always distinctly convex; fundus weakly concave. Sagittal section very similar to that figured by Wittmann et al. (1993: fig. 6P) for Heteromysis formosa S.I. Smith, 1873. Statolith formula $2+3+1+(8-13)=14-19$.

Nauplioid Larvae (Fig. 8M-N). Smooth cuticle all around, except for a pair of minute furcal processes and a number of minute setae on the blunt end of the abdomen.

\section{Distribution and habitat}

So far only known from euhaline, sublittoral waters of Curaçao $\left(12^{\circ} \mathrm{N}\right)$, where the mysids occur in swarms hovering during daytime around and between corals.

Mysidium (Mysidium) rickettsi Harrison \& Bowman, 1987

Mysidium rickettsi Harrison \& Bowman, 1987: 674-678, figs 1-3.

Mysidium rickettsi - Ferrari 2001: table 1 (in taxa list). — Ortiz 2001: 100. — Escobar-Briones 2002: 304. - Price 2004: 65 (in checklist). — Price et al. 2009: 232. — Gómez-Gutiérrez et al. 2014: 1027, table 3. — Ortiz et al. 2017a: table 1; 2017b: 78. — Ortiz \& Lalana 2018: 80.

Mysidium reckettsi - Gómez-Gutiérrez et al. 2014: 1009 (invalid spelling variant).

Mysidium ricketsi - Gómez-Gutiérrez et al. 2014: 1024 (invalid spelling variant).

\section{Material examined}

None.

\section{Type locality}

Gulf of California, Punta Marcial, 25.5167 N, 111.0167 W (Harrison \& Bowman 1987).

\section{Revised definition}

Adapted to the scheme in Table 2 by using published data (Harrison \& Bowman 1987; Ortiz et al. 2017b) on adults of both sexes: all features diagnosed above for genus and subgenus Mysidium Dana, 1852, with the reservation that the detailed structure of the setae on the merus of thoracic endopod 3 is unknown. Cornea calotte-shaped in dorsal view, its diameter 2.1 times as long as terminal segment of antennular trunk. Eyestalks smooth. Rostrum round-triangular, not extending beyond eyestalks. Appendix masculina obscurely bilobate, all along inner margins fringed by large setae; its length 1.5 times terminal segment of antennular trunk. Length of antennal scale four times maximum width; scale reaching well beyond antennular trunk. Median segment of mandibular palp with setae all along inner margin, whereas setae lacking on outer margin. Carpopropodus with two segments in thoracic endopods 1-2, 7-8, versus three segments in endopods 3-6. Basal segment is 0.6 times total length of carpopropodus of endopod 3. Male pleopod 1 stout, allusively bilobate. Sympod of male pleopod 4 without endite. Its exopod with basal 
Table 2. Diagnostic characters of the species of Mysidium Dana, 1852.

\begin{tabular}{|c|c|c|c|c|c|c|c|c|c|}
\hline 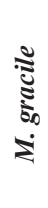 & 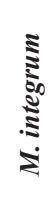 & 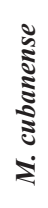 &  & 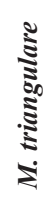 &  & : & 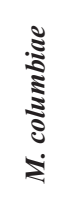 & 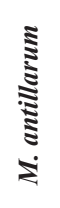 & : \\
\hline
\end{tabular}

\begin{tabular}{llllllllllll}
\hline Cornea & diameter is $(\mathrm{x})-\mathrm{times}$ & $1.7-3.2$ & $1.6-2.4$ & $2.6-4.1$ & $1.9-2.9$ & $1.7-2.5$ & 2.1 & 1.5 & $1.5-2.0$ & $1.4-1.7$ & 1.5
\end{tabular}

length of terminal segment of an-

tennular trunk in dorsal view

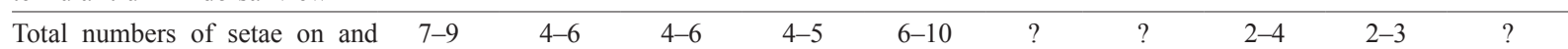

close to medio-terminal exten-

sion of male antennular trunk

(Fig. 1B)

\begin{tabular}{lllllllllll}
\hline Its largest seta is (x)-times length & $0.9-1.4$ & $0.3-0.5$ & $0.2-0.4$ & $0.1-0.3$ & $0.1-0.3$ & $?$ & $?$ & $0.1-0.2$ & 0.1
\end{tabular}

of mediodistal extension of male

antennular trunk

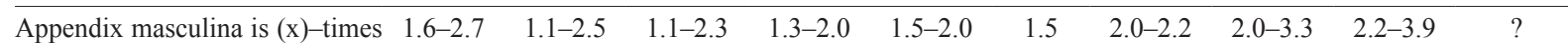

length of terminal segment of an-

tennular trunk

\begin{tabular}{lllllllllll}
\hline Antennal scale extends beyond yes yes & yes & yes & yes & yes & yes & yes & yes & nes
\end{tabular}
antennular trunk

\begin{tabular}{llllllllllllll}
\hline Antennal scale length is $(\mathrm{x})-$ & $4-6$ & $4-5$ & $4-6$ & $4-5$ & $5-7$ & 4 & 6 & $7-8$ & $7-11$
\end{tabular}

times maximum width

Median segment of mandibular yes yes yes yes $\quad$ yes $\quad$ no $\quad$ yes yes

palp with setae on outer margin

\begin{tabular}{lllllllllllll}
\hline About evenly rounded (1), mod- & 1 & 1 & 1 & 2 & 1 & $?$ & $?$ & 3 & 3
\end{tabular}

erately unevenly rounded (2)

or distally angular (3) hump on

outer face of terminal segment of

maxillula

\begin{tabular}{|c|c|c|c|c|c|c|c|c|c|c|}
\hline $\begin{array}{l}\text { Carpopropodus of third thoracic } \\
\text { endopod (n)-segmented }\end{array}$ & 3 & 3 & 3 & 3 & 3 & 3 & 2 & 3 & 3 & 3 \\
\hline $\begin{array}{l}\text { Basal segment is }(\mathrm{x}) \text {-times total } \\
\text { length of carpopropodus of third } \\
\text { thoracic endopod }\end{array}$ & 0.5 & 0.5 & 0.5 & 0.5 & $0.4-0.5$ & 0.6 & 0.8 & 0.5 & 0.5 & 0.4 \\
\hline $\begin{array}{l}\text { Numbers of serrated setae along } \\
\text { merus of third thoracic endopod }\end{array}$ & 0 & 0 & 0 & 0 & 0 & $?$ & 0 & $2-6$ & $2-7$ & $?$ \\
\hline $\begin{array}{l}\text { First pleopod rod-like (1) versus } \\
\text { bilobate ( } 2)\end{array}$ & $1-2$ & 2 & 2 & 1 & 2 & $1-2$ & 1 & 1 & 1 & $?$ \\
\hline $\begin{array}{l}\text { Medial margin of third male } \\
\text { pleopod with widening (1) versus } \\
\text { projecting endite (2) }\end{array}$ & 1 & 1 & 1 & 1 & 1 & 1 & 2 & 2 & 2 & $?$ \\
\hline Sympod of fourth male pleopod: & $0-1$ & $0-1$ & $0-1$ & $0-1$ & $0-1$ & 0 & 0 & 2 & $0-1$ & $?$ \\
\hline
\end{tabular}

without endite (0), with endite re-

duced to indistinct projection or

widening (1), with strong endite

(2)

\begin{tabular}{llllllllllll}
\hline Sympod of fourth male pleopod & 0 & 0 & 0 & 0 & 0 & 0 & 0 & $3-6$ & $3-7$
\end{tabular} with (n) setae on rostral face

\begin{tabular}{llllllllllllll}
\hline Exopod of fourth male pleopod & 4 & 4 & 4 & 4 & 4 & 4 & 4 & 3
\end{tabular}

(n)-segmented

\begin{tabular}{lllllllllllll}
\hline Basal segment is (x)-times total & $0.6-0.7$ & $0.5-0.6$ & $0.5-0.6$ & $0.5-0.6$ & 0.6 & 0.6 & 0.5 & $0.6-0.7$ & 0.7
\end{tabular} length of exopod of fourth male

pleopod

\begin{tabular}{llllllllllllll}
\hline Penultimate segment of exopod & 1 & 1 & 1 & 1 & 1 & 1 & 2 & 1 & 1
\end{tabular}

of fourth male pleopod with entire

(1) versus bifid (2) modified seta

\begin{tabular}{llllllllll}
\hline Endopod of fourth male pleopod & $0.1-0.2$ & $0.1-0.2$ & $0.1-0.2$ & $0.1-0.2$ & $0.1-0.2$ & $\approx 0.1$ & $\approx 0.2$ & $0.3-0.5$ & $0.3-0.4$
\end{tabular}

is (x)-times length of sympod 
Table 2 (continued).

\begin{tabular}{|c|c|c|c|c|c|c|c|c|c|c|}
\hline & 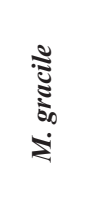 & 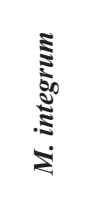 & 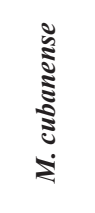 & 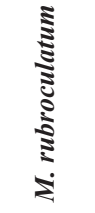 & 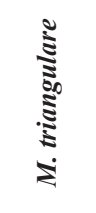 & 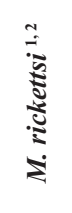 & $\frac{\mathfrak{z}}{\mathfrak{\Sigma}}$ & 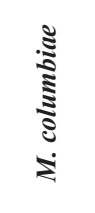 & 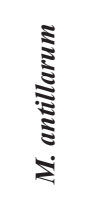 & 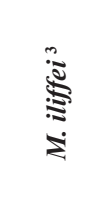 \\
\hline $\begin{array}{l}\text { Endopod of fourth male pleopod } \\
\text { with (n) setae }\end{array}$ & $5-8$ & $5-7$ & $5-7$ & $4-6$ & $5-7$ & 7 & 5 & $7-10$ & $5-12$ & $?$ \\
\hline $\begin{array}{l}\text { Lateral margins of telson with } \\
\text { spines (1) or laminae (2) }\end{array}$ & 1 & 1 & 1 & 1 & 1 & 1 & 2 & 1 & 1 & 2 \\
\hline $\begin{array}{l}\text { Numbers of spines or laminae on } \\
\text { each lateral margin of telson }\end{array}$ & $11-15$ & $13-25$ & $7-16$ & $8-12$ & $5-11$ & $\approx 19$ & $20-22$ & $8-12$ & $12-17$ & $\approx 9-11$ \\
\hline $\begin{array}{l}\text { Telson with distinct apical cleft } \\
\text { separating two broadly rounded, } \\
\text { apical lobes (0) versus telson } \\
\text { with shallow terminal indentation } \\
\text { (1), traverse terminal margin (2), } \\
\text { convex terminal margin (3), or } \\
\text { ending in a triangular projection (4) }\end{array}$ & 1 & $2-3$ & $2-3$ & $3-2$ & 4 & 3 & 3 & 0 & 0 & 0 \\
\hline $\begin{array}{l}\text { Terminal margin of telson with } \\
\text { series of acutely pointed (1) } \\
\text { versus blunt (2) laminae or spines }\end{array}$ & 2 & $1-2$ & $2-1$ & 2 & 2 & $1-2$ & 1 & 2 & 1 & 1 \\
\hline $\begin{array}{l}\text { Numbers of laminae or spines on } \\
\text { terminal margin of telson }\end{array}$ & $15-21$ & $12-20$ & $12-20$ & $11-18$ & $21-24$ & $\approx 24$ & $23-25$ & $22-30$ & $19-23$ & $\approx 17-22$ \\
\hline
\end{tabular}

Original data and from ${ }^{1)}$ Harrison \& Bowman 1987; ${ }^{2)}$ Ortiz et al. 2017a, 2017b; ${ }^{3)}$ Băcescu $1991 ;{ }^{1,2,3)}$ data partly derived from figures.

segment occupying $58 \%$ total length. Endopod reduced to lobe with $\approx 11 \%$ sympod length; apically with one long seta and more proximally six additional, smaller setae. Uropodal endopod $0.6-0.7$ times as long as exopod. Telson linguiform, tapering posteriorly, length 1.9 times maximum width near basis; lateral margins slightly convex, almost straight; terminal margin clearly convex, well rounded. Proximal half of lateral margins smooth, distal half with dense series of 30-37 short, blunt or pointed spines on each side; lateral margins each with about 19 spines, terminal margin with about 24 spines.

\section{Distribution and habitat}

East Pacific coast of Mexico: Gulf of California, Islas Tres Marías, 21-26 N. Occurring in shallow, coastal marine waters where it forms dense epibenthic swarms (Gómez-Gutiérrez et. al. 2014). Also collected with night light at surface and from fish stomachs (Harrison \& Bowman 1987; Ortiz et al. 2017b).

Occimysidium Wittmann subgen. nov. urn:lsid:zoobank.org:act:EE9F05D3-29B5-4B95-BC0D-2A6756AAECE5

\section{Type species}

Mysidium pumae Ortiz, Hendrickx \& Winfield, 2017, by monotypy.

\section{Etymology}

Noun in nominative singular with neutral ending, formed by amalgamation of the Latin noun 'occidens' with the generic name Mysidium, referring to the occurrence on the west coast of America.

\section{Diagnosis}

Subdivision of the genus Mysidium Dana, 1852, characterized by two-segmented carpopropodus of third thoracic endopod; merus of this endopod without serrated setae. Third male pleopod with distinct 
endite at about $2 / 3$ distance from basis of medial margin. Sympod of fourth male pleopod without setae on rostral face. Its exopod four-segmented; basal segment with $0-1$ seta, second segment without seta, subterminal segment with bifid modified seta, terminal segment with undivided modified seta. Telson entire (not incised).

\section{Distribution}

As for type species.

Mysidium (Occimysidium) pumae Ortiz, Hendrickx \& Winfield, 2017 comb. nov.

Mysidium pumae Ortiz et al., 2017a: 114-117, table 1, figs 1-4.

Mysidium pumae - Ortiz et al. 2017b: 77. — Ortiz \& Lalana 2018: 80.

\section{Material examined}

None.

\section{Type locality}

Pacific coast of Mexico, Mazatlán Harbor, 23.1814 N, 106.4242 W (Ortiz et al. 2017a).

\section{Revised definition}

Adapted to the scheme in Table 2 by using published data (Ortiz et al. 2017a, 2017b) on adults of both sexes: all features diagnosed above for the genus Mysidium Dana, 1852, and its new subgenus Occimysidium. Cornea crescent-like in dorsal view, with 'diameter' 1.5 times as long as terminal segment of antennular trunk. Eyestalks smooth. Rostrum triangular, apically bluntly pointed, not extending beyond eyestalks. Appendix masculina with separate inner and distal tufts of setae; its length 2.0-2.2 times terminal segment of antennular trunk. Length of antennal scale six times maximum width; scale reaching well beyond antennular trunk. Median segment of mandibular palp with setae on both margins. Carpopropodus of first to eighth thoracic endopods 2, 2, 2, 3, 3, 3, 2, and two-segmented, respectively. Basal segment occupies 0.8 times total length of carpopropodus of endopod 3. Pleopods 1-2, 5 rodlike, not considering the reduced endopodal portion (pseudobranchial lobe); male pleopod 3 with an additional, small endite. Length of male pleopods increases in order of pleopods 1, (subequal 2, 3,5), 4. Sympod of male pleopod 4 without endite. Exopod with basal segment occupying 54\% total length. Endopod reduced to lobe with $\approx 22 \%$ sympod length; apically with one long seta and more proximally four additional shorter setae. Uropodal endopod 0.7 times as long as exopod. Telson spatulate, caudally gradually narrowing; length 2.3 times maximum width near basis; terminal margin convex, evenly rounded. Proximal $51-52 \%$ of lateral margins smooth, distal portion of each margin with continuous series of 20-22 acute laminae. Terminal margin lined by 23-25 more densely set, acute laminae. These latter laminae more slender than the neighboring latero-terminal laminae.

\section{Distribution}

So far known only from type locality.

Orientomysidium Wittmann subgen. nov. urn:1sid:zoobank.org:act:E269F7A6-0187-4AD0-9D64-24C700D5126D

\section{Type species}

Diamysis columbiae Zimmer, 1915, by present designation. This taxon acknowledged in revised combination as Mysidium (Orientomysidium) columbiae (Zimmer 1915). 


\section{Etymology}

Noun in nominative singular with neutral ending, formed by amalgamation of the Latin adjective 'orientale' with the generic name Mysidium, referring to the occurrence on the east coast of America.

\section{Diagnosis}

Subdivision of the genus Mysidium Dana, 1852, characterized by three-segmented carpopropodus of third thoracic endopod; merus of this endopod with serrated setae. Third male pleopod with strong endite at about $50-60 \%$ distance from basis of medial margin. Sympod of fourth male pleopod with series of setae on rostral face. Its exopod three-segmented; proximal segment without seta; the two distal segments each with one unbranched modified seta. Telson with terminal cleft.

\section{Distribution}

Littoral and sublittoral waters at Atlantic coasts of tropical America $\left(24^{\circ} \mathrm{N}\right.$ to $\left.8^{\circ} \mathrm{S}\right)$, including Gulf of Mexico and Caribbean.

Mysidium (Orientomysidium) columbiae (Zimmer, 1915) subgen. et comb. nov. Figs 9, 13E-J

Diamysis columbiae Zimmer, 1915a: 172-174, figs 23-29 (senior synonym in outdated generic combination).

Diamysis columbiae - Zimmer 1915b: 215 (in synonymy). — Illig 1930: 599 (in synonymy). — Prieto et al. 2009 (in synonymy).

Mysidia columbiae - Zimmer 1915b: 215, fig. 18 (combination with generic junior homonym); 1918: 26. — Illig 1930: 599 (in key). - W.M. Tattersall 1951: 222 (in homonymy).

Mysidium columbiae - W.M. Tattersall 1951: 222, 223 (revised combination). — Davis 1966: figs 1-5. — Brattegard 1969: 86, fig. 27B; 1974a: 69; 1974b: 102, table 1; 1975: 112. — Mauchline 1972: table 3; 1973: tables 2, 4; 1980: 338 (in list). — Băcescu \& Ortiz 1984: 22 (in key). — Harrison \& Bowman 1987: 678 (in comparison). — Modlin 1987: 115; 1990: figs 1, 3; 1993: 25. — Ortiz \& Lalana 1988: 14 (in list); 2018: fig. 10A. - Zoppi de Roa et al. 1989: fig. 2B. - Markham et al. 1990: 411. - Băcescu 1991: 3, fig. 1J. - Escobar-Briones \& Soto 1991: table 1. - Ariani et al. 1993: table 1. — Ortiz 2001: 100 (in list). — Price et al. 2002: 44. — Price \& Heard 2004: 154. — Sorbe et al. 2007: table I. — Prieto et al. 2009: 33. — Miyashita \& Calliari 2014: 9. — Wittmann et al. 2014: 350. — Ortiz et al. 2017a: table 1; 2017b: fig. 3A. — Esteves-Astudillo et al. 2017: 62. Mysidium colombiae - Harrison \& Bowman 1987: 674, 678 (invalid spelling variant). — Price \& Heard 2004: fig. 3I; 2009: 938 (in list).

non Mysidium columbiae - Brattegard 1969: fig. 27E.

\section{Type material examined}

The three vials are from the same sample labelled "Cartagena Kolumbien G. Gagzo leg. 18. IX. 1905 ded. 7. XI. 1906", this material is brittle and delicate, limiting examination. The two specimens from vial 14074 with body parts and appendages sticking together. The respective missing appendages suggest that the lectotype has been partly dissected and figured by Zimmer (1915a: figs 23-29).

Lectotype (by present designation)

COLOMBIA - $\hat{\gamma}$ ad. bl $4.4 \mathrm{~mm}$; registered at the ZMH as "Diamysis columbiae Zimmer, lectotype by present designation"; $10.37^{\circ} \mathrm{N}, 75.52^{\circ} \mathrm{W}$; ZMH K-14073a 


\section{Paralectotypes}

COLOMBIA $\bullet ~ 1 q$ ad. bl $4.8 \mathrm{~mm}$ carrying two postnauplioid larvae; ZMH K-14073b $\bullet 1$ đad. bl $4.6 \mathrm{~mm}, 1$ ㅇ ad. bl $5.0 \mathrm{~mm}$; ZMH K-14074.

\section{Other material examined}

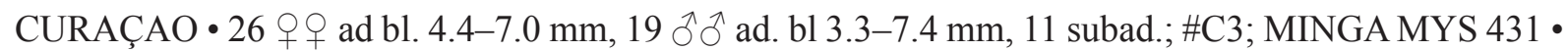
13 우 ad. bl 5.9-7.0 mm, 7 ठิ $\widehat{乛}$ ad. bl 5.8-7.8 mm, 8 subad.; \#C5; NHMW 26479.

BONAIRE • 24 q $q$ ad. bl 4.6-5.3 mm, 22 ठิ $\widehat{\text { ô }}$ ad. bl 3.9-6.9 mm, 61 subad.; \#B11; ZMH K-55263 •

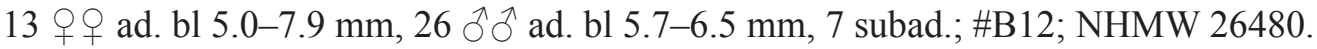

\section{Type locality}

Cartagena at the Caribbean coast of Colombia (Zimmer 1915a). Coordinates estimated by present authors are about $10.37^{\circ} \mathrm{N}, 75.52^{\circ} \mathrm{W}$.

\section{Revised definition}

All features diagnosed above for the genus Mysidium Dana, 1852, and its new subgenus Orientomysidium. Cornea globose in lateral view; calotte-shaped in dorsal view, with diameter 1.5-2.0 times as long as terminal segment of antennular trunk. Eyestalks smooth. Rostrum triangular, with concave lateral margins, apically bluntly to acutely pointed, not or weakly extending beyond basis of eyestalks. Anterolateral edges of carapace rounded. Only males with anterior margin of antennular trunk dorsally with rounded, shield-like, mediodistal extension (Fig. 9A-B) bearing 2-4 setae. The largest seta 0.1-0.2 times extension length. Appendix masculina bilobate, 2.0-3.3 times as long as terminal segment of antennular trunk; all along with brush of long setae. Length of antennal scale 7-8 times maximum width; scale reaching far beyond antennular trunk. Median segment of mandibular palp with setae on both margins. Distally angular hump on outer face of terminal segment of the maxillula. Carpopropodus of thoracic endopods $1-8$ with $2,2,3,3-2,2-3,2-3,2-3$ or $2-3$ segments, respectively. Series of 2-6 serrated setae (Fig. 9D) along merus of third thoracic endopod. Basal segment occupies half total length of carpopropodus of endopod 3. Pleopod 1 rod-like in both sexes, not considering the weak (sub) median widening at its vestigial endopodal portion (Fig. 9F). Sympod of male pleopod 4 with strong endite at $2 / 5$ sympod length from basis and with longitudinal series of 3-6 plumose setae on rostral face. Exopod with basal segment occupying 64-72\% total length. Endopod reduced to lobe with $27-48 \%$ sympod length; with 7-10 barbed setae of various sizes. Endopod of uropods $0.6-0.7$ times as long as exopod. Telson subrectangular, length 1.4-1.8 times maximum width near basis. Its lateral margins convex along proximal third; proximal $61-73 \%$ of lateral margins smooth, distal portion of each margin with continuous series of 8-12 acute spines. Cleft penetrating 13-15\% telson length; cleft separating two broadly rounded, apical lobes; cleft and terminal portion of lobes densely lined in continuous series by a total of 22-30 stout, blunt laminae.

\section{Description of type (Fig. 9A)}

All available features fit within the diagnosis. Antennular trunk extends $25-47 \%$ its length beyond (artificially aligned) eyes. Sympod of antenna produced into spiniform extension on outer distal corner. Apical segment of maxillary palp about two times as long as basal segment. Carapace posteriorly emarginate, with well-rounded latero-terminal lobes; cervical sulcus strong. Dactylus of thoracic endopods 1-2 with moderately long, strong claw; dactylus 3-7 with long, needle-like claw; dactylus 8 with short seta-like claw. Sympod of fourth male pleopod with 3-4 plumose setae (this range wider in non-types examined) on rostral face plus 1-2 small, barbed setae on inner margin. Pleonites $1-5$ are $0.5-0.8,0.5-0.8,0.6-0.8,0.6-0.8$ or $0.8-1.1$ times the length of pleonite 6 , respectively. Scutellum paracaudale triangular with blunt to acute apex; both margins weakly concave to weakly convex. 


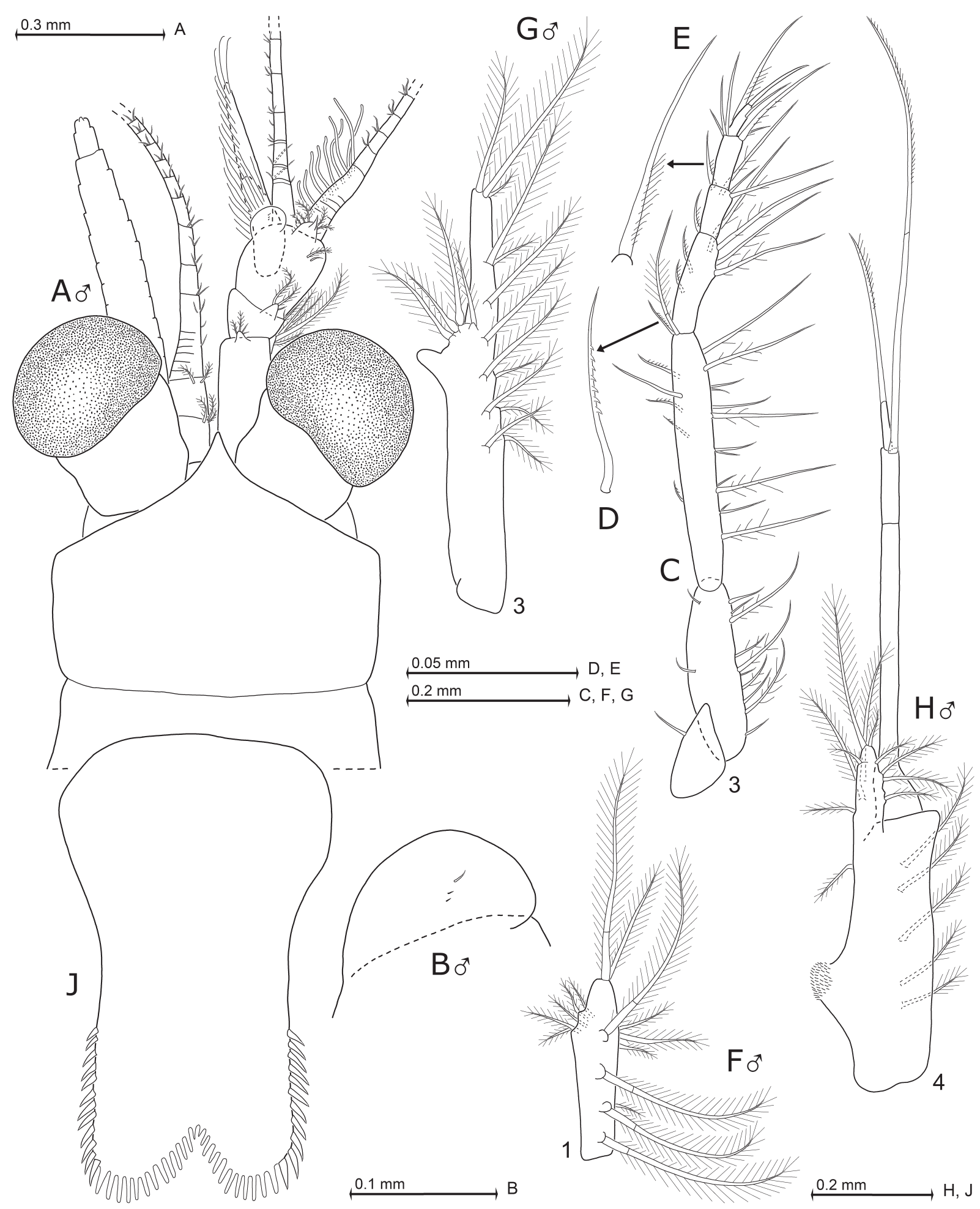

Fig. 9. Mysidium columbiae (Zimmer, 1915), lectotype from Cartagena in Colombia (A) and non-types

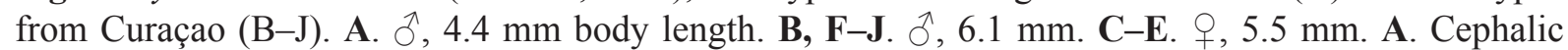
region; left antennula and setae of antennal scale omitted. B. Mediodistal extension of right antennular trunk, dorsal view. C. Third thoracic endopod, caudal view. D-E. Details of panel (C) showing modified setae. F-G. Pleopods 1 and 3, rostral view. H. Pleopod 4, caudal view. J. Telson. Sample affiliation: Colombia - type locality (A), Curaçao \#C3 (B-J). 
Uropodal endopod 0.9-1.1 times, exopod 1.2-1.5 times as long as pleonite 6. Exopod extends 0.3-0.4 times its length beyond endopod, or 0.7-0.8 times beyond telson; endopod 0.4-0.6 times its length beyond telson. Telson with $0.5-0.7$ times as long as exopod of uropods, $0.5-0.9$ times endopod or $0.6-0.9$ times pleonite 6 .

\section{Notes on additional material (Figs 9B-J, 13E-J)}

Adult females of present material with 4.4-7.9 $\mathrm{mm}(\mathrm{n}=76)$ body length, males 3.3-7.8 $\mathrm{mm}(\mathrm{n}=74)$. Numbers of serrated setae (Fig. 9C-D) along the merus of thoracic endopod 3 increase with increasing body size; also numbers of endopods with any setae of that type increase with body size, i.e., pertaining only to thoracopod 3 in smaller individuals and successively to thoracopods 4-7 as individuals become larger. Endopod 8 (when stretched) reaching backwards at most to the end of pleonite 4 and forwards to mandibles; its carpopropodus measures $0.4-0.5$ times telson length. Male pleopod 4 comparatively short; exopod reaching at most to basal third of pleonite 6, its subapical seta up to terminal third. Endopod of male pleopod 4 (Fig. 9H) with the most distal seta 1.4-4.4 times endopod length. Sympod with field of scales on its endite. Statoliths composed of fluorite.

Foregut (Fig. 13E-G) closely similar to that of M. antillarum sp. nov. (Fig. 11A-E). As main differences from this species, $M$. columbiae shows different structure and variable numbers of large spines: on each lateral half there are 2-4 apically pronged spines on posterior part of lateralia, the teeth of these spines with dense sets of secondary denticles (Fig. 13F); and there are 1-2 larger, apically pronged, serrated spines on dorso-lateral infolding, the latter spines flatter, more clavate, and with more slender teeth on basal $2 / 3$ (Fig. 13G).

\section{Notes on individual development}

Nauplioid larvae (Fig. 13H) with smooth cuticle all around, except for a pair of minute furcal processes and a number of minute setae on the blunt end of the abdomen (Fig. 13J). Davis (1966: fig. 4) already reported apical, furcal 'spines' in nauplioids of $M$. columbiae from Jamaica. In non-types of the present material, the differentiation of male sexual characteristics is visible in early subadults as small rudiments of penis and appendix masculina and of a bifid fourth pleopod. At this stage the exopod of pleopod 4 is less than $3 / 2$ as long as endopod and the endite of the sympod is missing or indistinct. In the course of further development a distinct endite (representing an important diagnostic character) becomes visible as soon as the exopod exceeds two times the length of the endopod.

\section{Distribution and habitat}

From $24^{\circ} \mathrm{N}$ to $8^{\circ} \mathrm{S}$ in coastal waters of Bahamas, Caribbean, southern Gulf of Mexico, and Brazil (Price \& Heard 2004; Miyashita \& Calliari 2014). The present samples from Curaçao and Bonaire fit within this geographic range. The present material was encountered at a depth of 3-26 m, during daytime in swarms hovering around and between corals. During the night dispersed over the sea floor.

$$
\begin{gathered}
\text { Mysidium (Orientomysidium) antillarum Wittmann sp. nov. } \\
\text { urn:1sid:zoobank.org:act:7CCD97DD-6848-46AF-B806-82D93D3FF3BA }
\end{gathered}
$$

Figs $10-12,13 \mathrm{~A}-\mathrm{D}$

\section{Etymology}

The species name is a Latinized Spanish noun in the genitive plural, referring to the occurrence at islands of the Antilles.

Type material examined (by present designation)

Holotype

CURAÇAO - $\hat{\sigma}$ ad. bl $7.3 \mathrm{~mm}$; shallow marine waters of Curaçao, Reef Sint Marie; $12.2122^{\circ} \mathrm{N}$, 69.0850 W; \#C6; NHMW 26484. 


\section{Paratypes}

CURAÇAO • 48 우 ad. bl $6.2-8.0 \mathrm{~mm}, 37$ $\widehat{\partial}$ ad. bl 5.1-7.5 mm, 11 subad.; same locality data as for holotype; \#C6; MINGA MYS 433, NHMW 26485, ZMH K-55258.

\section{Other material examined}

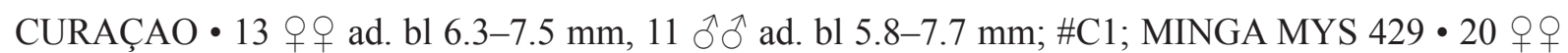

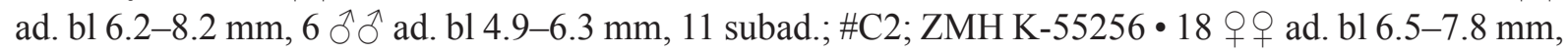

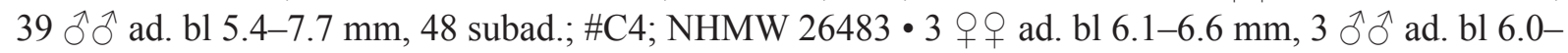
$6.3 \mathrm{~mm}, 109$ subad.; \#C7; MINGA MYS $435 \bullet 1$ ㅇ subad. bl $4.5 \mathrm{~mm}$; \#C8 • 24 우 ㅇa. bl 6.3-8.1 mm,

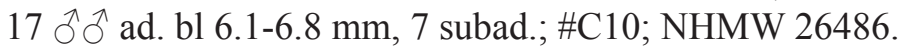

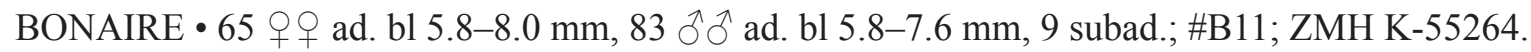

\section{Definition}

All features diagnosed above for the genus Mysidium Dana, 1852, and its new subgenus Orientomysidium. Cornea globose in lateral view, calotte-shaped in dorsal view, with diameter 1.4-1.7 times as long as terminal segment of antennular trunk. Eyestalks smooth. Rostrum triangular, apically rounded or pointed, not extending beyond basis of eyestalks. Antero-lateral edges of carapace rounded. Only males with anterior margin of antennular trunk dorsally with rounded, shield-like, mediodistal extension (Fig. 10A-B) bearing 2-3 setae. The largest seta 0.1 times extension length. Appendix masculina 2.23.9 times terminal segment of antennular trunk; its shorter, dorsal lobe with brush of long setae, its longer ventral lobe with less dense set of shorter setae. Length of antennal scale 7-11 times maximum width, scale clearly reaching beyond antennular trunk. Median segment of mandibular palp with setae on both margins. Distally angular hump on outer face of terminal segment of maxillula. Carpopropodus of thoracic endopods $1-8$ with 2, 2, 3, 3, 2-3, 2-3, 2-3 or 2 segments, respectively. Basal segment occupies half total length of carpopropodus of endopod 3. Series of 2-7 serrated setae (Fig. 12B) along merus of third thoracic endopod. Pleopod 1 rod-like in both sexes, not considering the weak (sub)median widening at its vestigial endopodal portion (Fig. 12D, G). Sympod of male pleopod 4 with longitudinal series of 3-7 plumose setae on rostral face; without or with an indistinct medial widening (endite) at $1 / 3$ of sympod length from basis. Exopod with basal segment occupying 69-73\% total length. Endopod reduced to a terminally rounded lobe with 29-41\% sympod length; endopod with 5-12 mostly large, plumose setae of various sizes. Endopod of uropods $0.6-0.8$ times as long as exopod. Telson subrectangular with apical cleft. Telson length 1.4-1.7 times maximum width near basis. Its lateral margins convex along proximal third and smooth along proximal 51-58\%; distal portion of each margin with dense, continuous series of 12-17 acute spines. Subtriangular apical cleft penetrating 11-14\% telson length; cleft separating two broadly rounded, apical lobes; cleft and terminal portion of lobes densely lined in continuous series by a total of 19-23 (sub)acutely pointed, stout laminae.

\section{Description}

SizE. Adult females 5.8-8.2 mm $(\mathrm{n}=191)$, males 4.9-7.7 mm $(\mathrm{n}=197)$.

Antennal appendages (Fig. 10A-B, F-G). Antennular trunk extends 35-56\% its length beyond (artificially aligned) eyes. First to third segments occupy $47-52 \%, 14-18 \%$ or $30-37 \%$ total length of trunk, respectively. Trunk dorsally with forward-directed small, setose lobes near terminal margin of each segment: two lobes from the basal, one from the median, and one from the terminal segment (not counting the mediodistal extension of the anterior margin in males). Appendix masculina 0.7-1.4 times total trunk length, antennal scale 1.2-1.6 times trunk. Sympod of antenna (Fig. 10G) produced into spiniform extension on outer distal corner. Antennal scale with terminal segment occupying 10-14\% total length and bearing five plumose setae. 


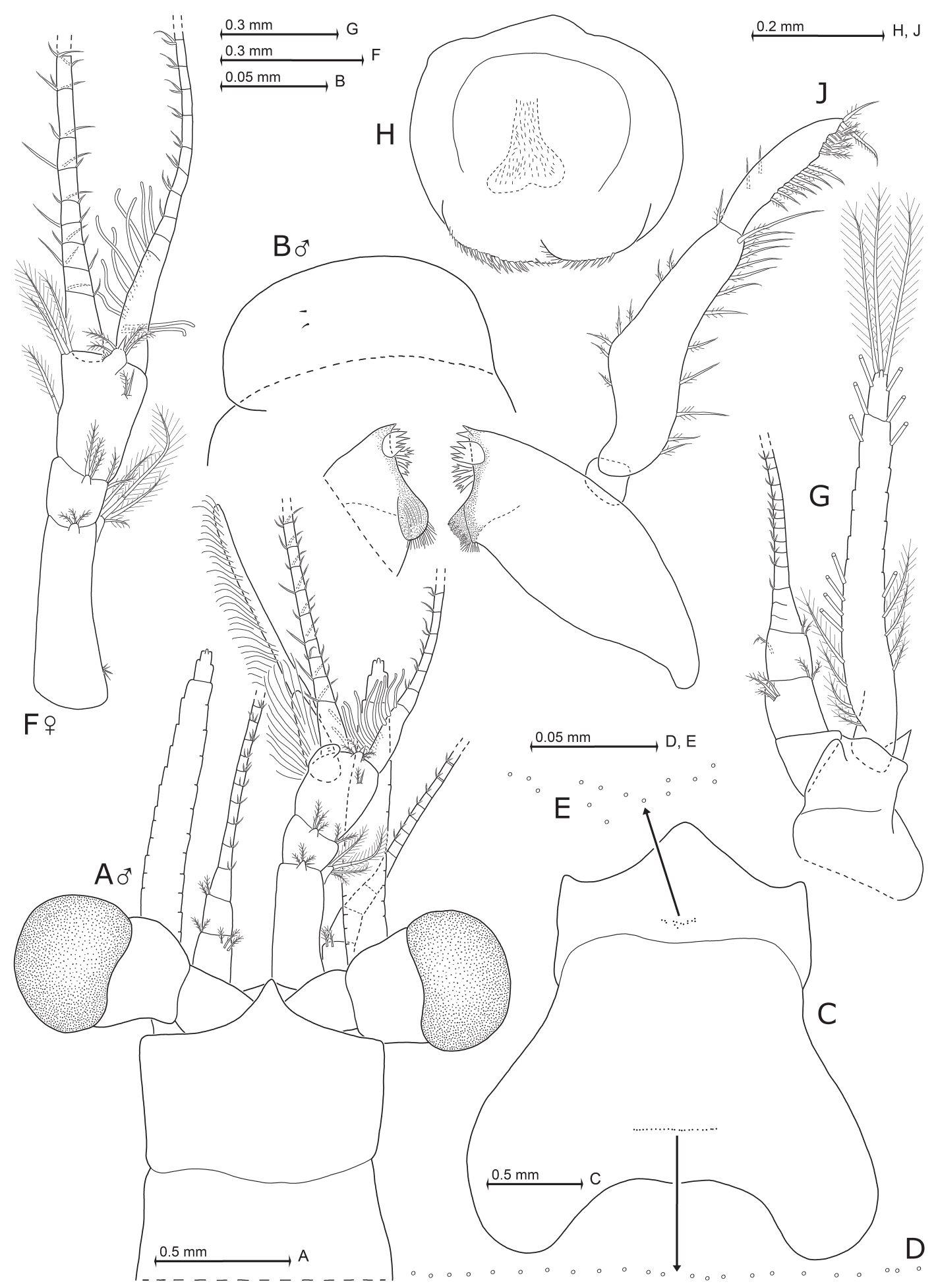

Fig. 10. Mysidium antillarum Wittmann sp. nov., from Curaçao, holotype (A) and paratypes (B-J).

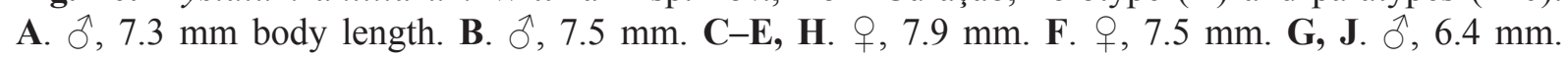
A. Cephalic region; left antennula and setae of antennal scale omitted. B. Mediodistal extension of left antennular trunk, dorsal view. C. Carapace expanded on slide. D-E. Details of panel (C) showing cardial (D) and cervical (E) pore groups; pore diameters not to scale. F. Right antennula of female, dorsal view. G. Right antenna, dorsal view. H. Labrum, ventral view. J. Left mandible with right masticatory process, caudal view. 
Mouth ParTs (Figs 10H, J, 11F-H). Mandibular palp (Fig. 10J) without spines; terminal segment with strong, modified, bent seta at apex, and barbed setae along inner and outer margins. Median segment of palp with angular, medially directed dilatation, both its margins setose. Proximal segment normal, with smooth margins. Distal segment of maxillula (Fig. 11G) terminally with strong spines, subterminally with one barbed seta; tip of endite of maxillula with apically modified setae (armed with stiff barbs) plus several setae with normal, fine barbs. Maxilla (Fig. 11H) with well-developed exopod, moderately large, two-segmented palp and three apically setose endites. Exopod with maximum width in submedian portions; its outer margin all along with continuous series of plumose setae. Basal segment of palp with three barbed setae. Apical segment about two times as long as basal segment. Length of apical segment 1.9-2.5 times maximum width. Apical segment densely setose on terminal margin but lined by small hairs along more than basal half of inner margin; apex with two strong, modified setae bearing strong, spine-like barbs along distal third of their inner margin.

Foregut (Fig. 11A-E). Setae, but no spines, close to inlet of oesophagus. Primary cardiac filter formed ventrally by dense combs of stiff setae behind this inlet. Lateralia and superomedianum densely covered by spines and/or setae. Apically coronate plus apically, weakly (Fig. 11B) to strongly (Fig. 11E) pronged, slender spines on anterior and median parts of lateralia. These spines with numerous minute denticles along distal $60-80 \%$ of their shaft. Two powerful, stout, apically pronged, serrated spines (Fig. 11C) on posterior part of lateralia; one additional, longer, more strongly serrated spine (Fig. 11D) of that type on the dorso-lateral infolding; yielding a total of six such powerful spines. Secondary filter formed by dense rows of setae in pyloric part of foregut.

Thorax of both SEXes (Figs 10C-D, 11J-K, 12A-C, 13A). Carapace (Fig. 10C) posteriorly emarginate, with well-rounded latero-terminal lobes; cervical sulcus strong; roughly V-shaped group of 10-16 pores (Fig. 10E) in front of cervical sulcus, transverse linear series of 16-23 pores (Fig. 10D) in cardial position (above heart). Sternites (Fig. 11J) smooth; a plumose seta accompanied by 1-2 shorter barbed setae on the joint between each sternite and its thoracopod. Endopod and exopod sizes increase from thoracopods 1 to 5 and decrease from 5 to 8 . Basal plate of exopods with large, well-rounded laterodistal expansion in exopods 1-7. Flagellum 8-segmented in exopods 1 and 8, versus 9-segmented in remaining exopods. First thoracic epipod bilobate, with smooth margins, without seta. First endopod (Fig. 11J) with well-developed, setose endites from basis, ischium, merus. Endopods 1-2 with large dactylus and strong claw. Dactylus of endopod 2 with 4-6 modified and several smooth setae, no spine-like setae; modified setae each with two dense rows of strong, acute barbs along their median to subterminal portions. Numbers of serrated setae (Fig. 12B) along the merus of thoracic endopod 3 increase with increasing body size; also numbers of endopods with any setae of that type increase with body size, i.e., pertaining only to thoracopod 3 in smaller individuals and successively to thoracopods 4-8 as individuals become larger. Endopods 3-7 with less stout, well-developed dactylus bearing a long, needle-like claw; endopod 8 (Fig. 13A) with even smaller dactylus and short seta-like claw. Endopod 8 (when stretched) reaching backwards at most to middle of pleonite 4 and forwards to mandibles; its carpopropodus measures $0.3-0.5$ times telson length.

Thoracopods of Females (Fig. 12C). Basal plate of exopod 8 with short to indistinct latero-distal expansion. The oostegites from thoracopods $7-8$ densely fringed with setae, together forming a large brood chamber. Thoracopod 6 with rudimentary oostegite bearing 2-4 setae at apex. These setae spinulose at least along their apical third. More such setae present in proximal portions of the oostegite from thoracopod 7.

THORACOPODS OF MALES AND PENIS (Fig. 13A). Basal plate of exopod 8 with distinct latero-distal expansion. Penes tubular, 0.7-0.9 times as long as merus of endopod 8. Penes apically bilobate, with row of 5-9 


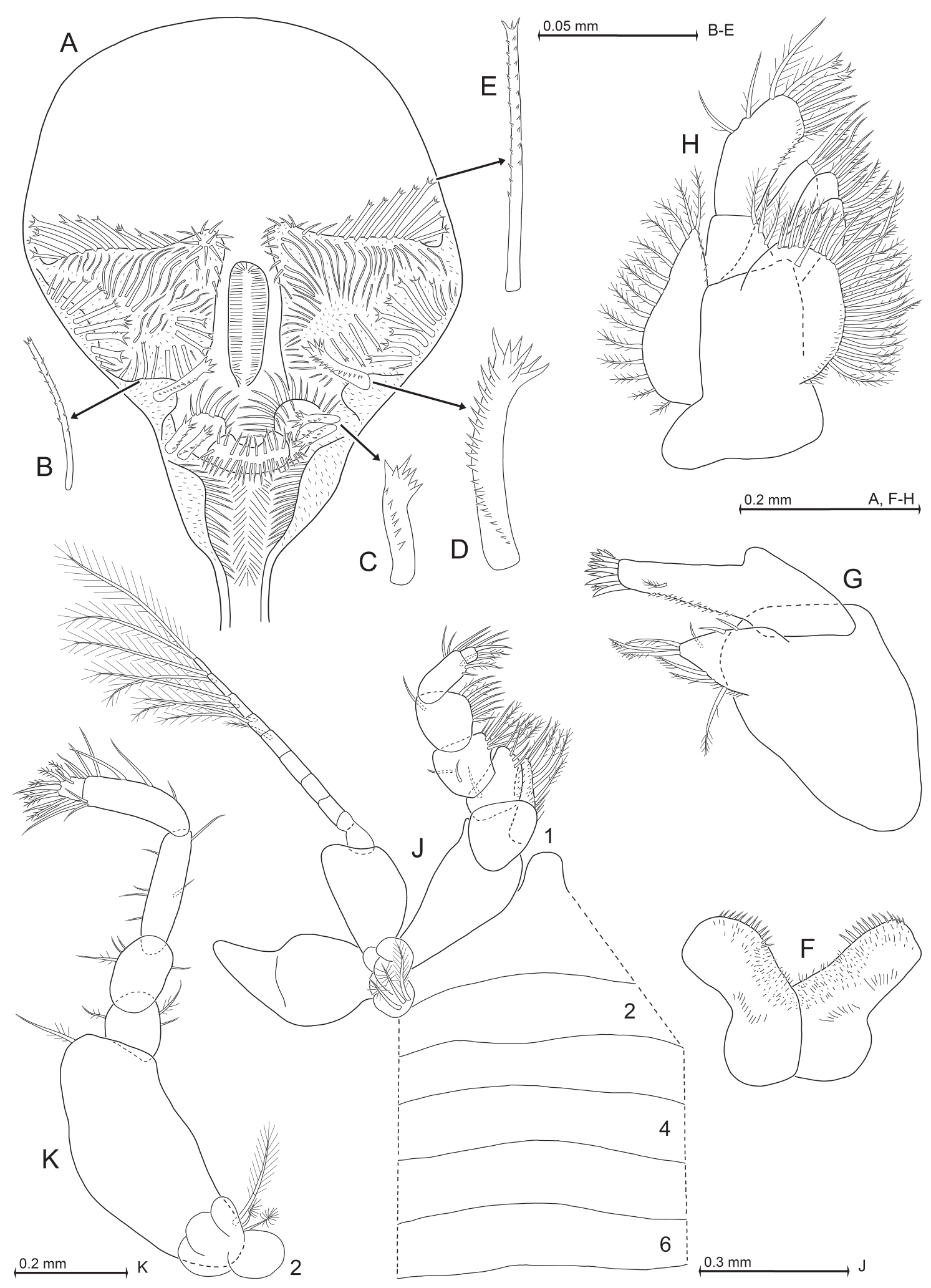

Fig. 11. Mysidium antillarum Wittmann sp. nov., from Curaçao, paratypes. A-E, G, J. $९, 7.9 \mathrm{~mm}$ body length. F, K. J, $7.5 \mathrm{~mm}$. H., , $7.5 \mathrm{~mm}$. A. Foregut; dorsal wall and some spines of superomedianum omitted. B-E. Details of panel (A) showing modified spines. F. Labium, caudal view. G. Maxillula, rostral view. H. Maxilla, rostral view. J. First thoracopod (caudal view) with sternites 1-6 (ventral view). K. Second thoracic sympod with endopod, rostral view. 


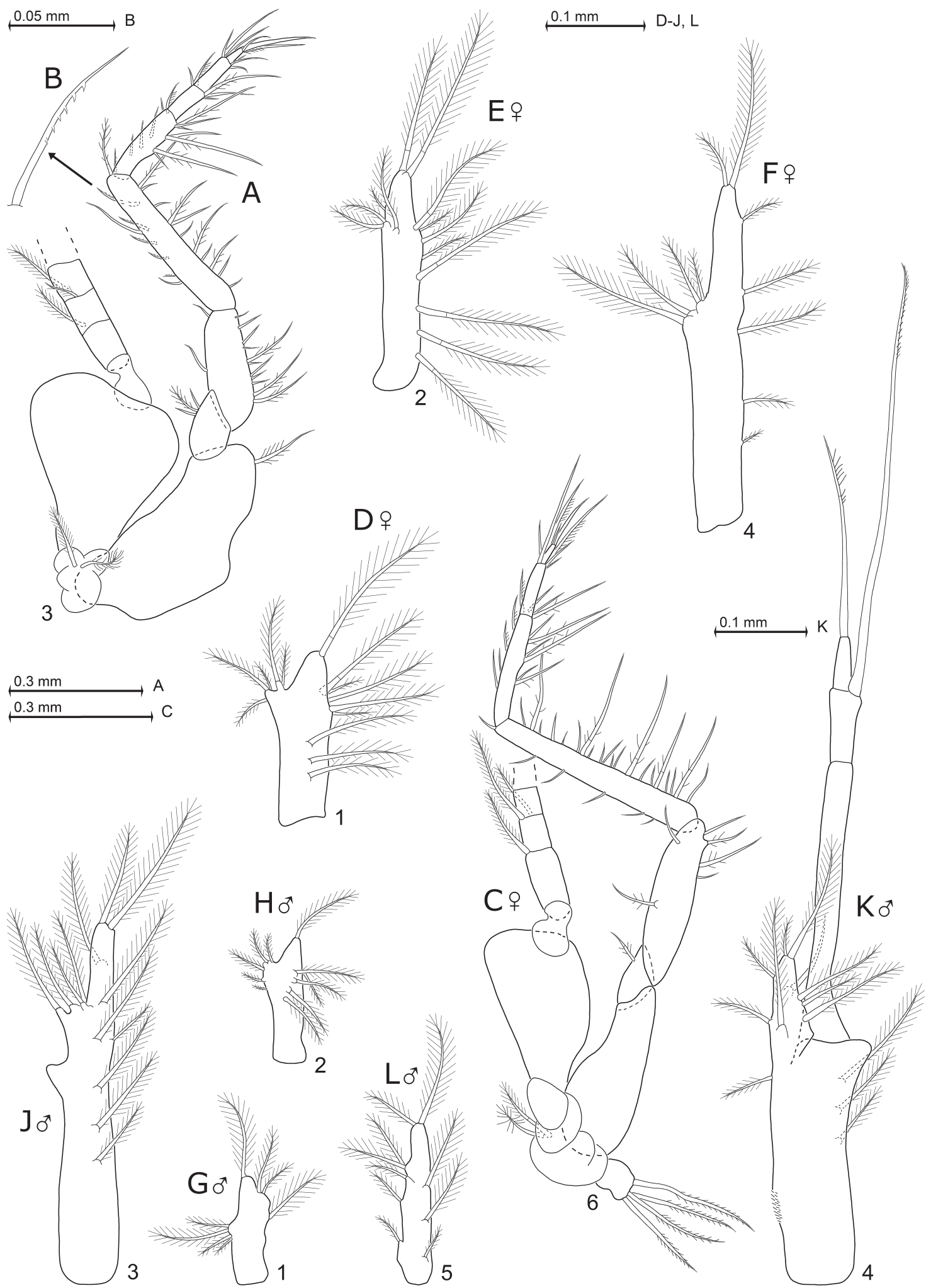

Fig. 12. Mysidium antillarum Wittmann sp. nov., from Curaçao, paratypes. A-B. $\hat{\jmath}, 7.5 \mathrm{~mm}$ body


caudal. B. Detail of panel (A) showing modified seta from merus. C. Sixth thoracopod with rudimentary oostegite, rostral view. D-F. Series of female pleopods 1, 2, 4, rostral view. G-J, L. Series of male pleopods 1-3, 5, rostral view. K. Male pleopod 4, caudal view. 
smooth, bent setae flanking the ejaculatory opening. One or two additional, smaller setae subapically on margin opposite bent setae.

Pleon (Figs 12D-L, 13B-D). Pleonites 1-5 are $0.5-0.6,0.6,0.6,0.6$ or 0.7 times the length of pleonite 6 , respectively. Size increases from pleopods 1 to 4, with pleopod 5 ranging between 2 and 3 in both sexes. Pleopods 1-3 with a ventro-laterally directed fan of plumose setae. Setae of pleopod 1

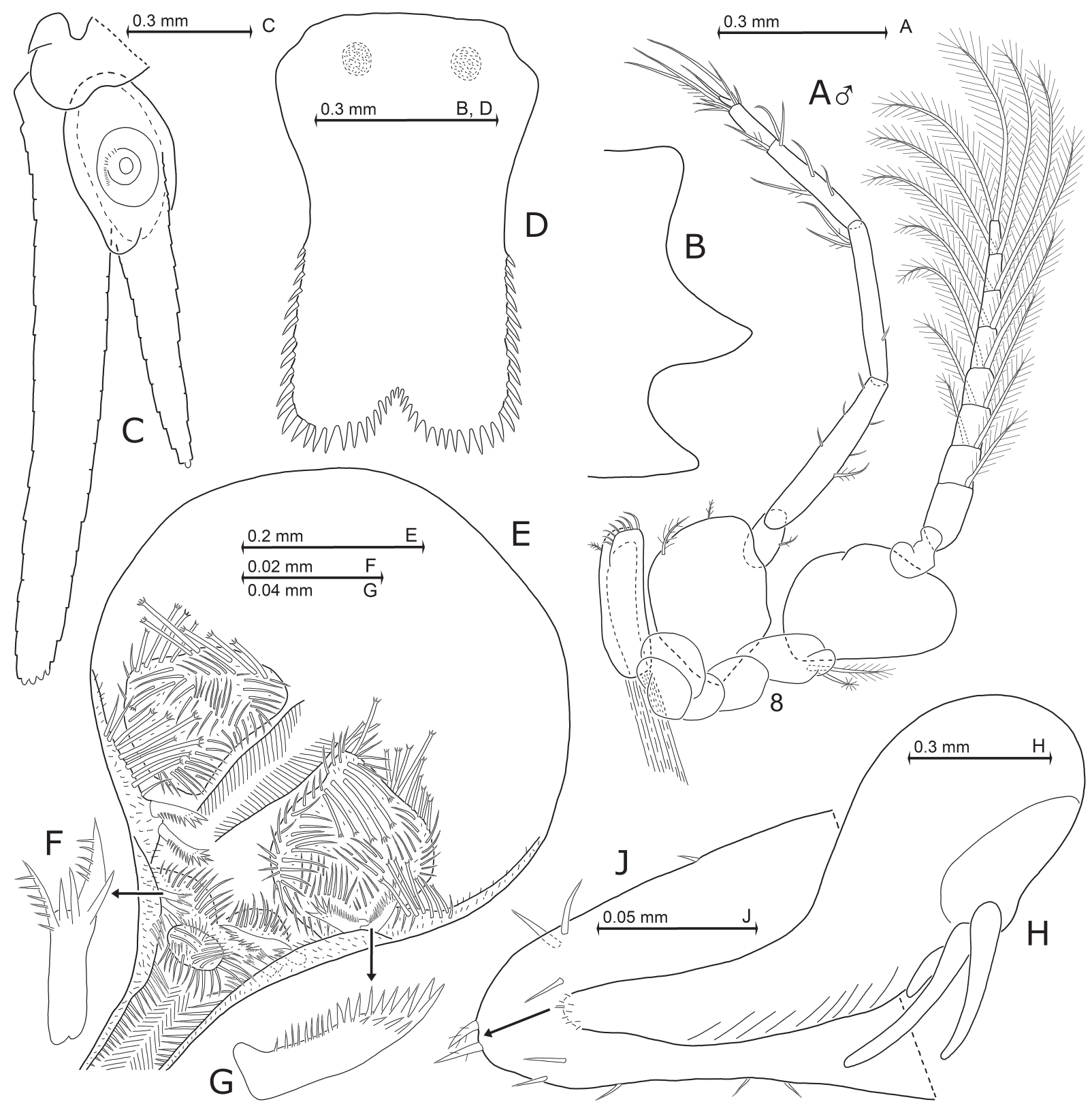

Fig. 13. Mysidium antillarum Wittmann sp. nov., holotype (A), paratypes (B-D) and M. columbiae

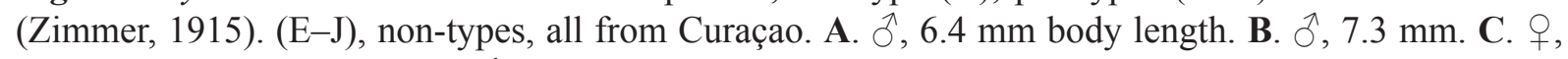
$7.9 \mathrm{~mm}$. D. $9,7.5 \mathrm{~mm}$. E-G. O, $6.1 \mathrm{~mm}$. A. Eighth thoracopod with penis, rostral view. B. Scutellum paracaudale, lateral view. C. Uropods, ventral; setae omitted. D. Telson. E. Foregut; dorsal wall omitted. F-G. Details of panel (E) showing modified spines. H. Nauplioid larva at substage N3, lateral view. J. Detail showing tip of abdomen in another nauplioid specimen. Sample affiliation: Curaçao - type locality \#C6 (A-D); Curaçao \#C3 (E-G), \#C5 (H-J). 
(Fig. 12D, G) not larger than those of pleopods 2, 3, 5. Female pleopods 1-5 (Fig. 12D-F) and male pleopods 1-2, 5 (Fig. 12G-H, L) vestigial, rod-like, not considering the weak (sub)median widening, if any, at the vestigial endopodal portion. Male pleopod 3 (Fig. 12J) essentially rod-like as well, yet with hump-like endite at $60 \%$ pleopod length from basis. Male pleopod 4 reaching with its subapical seta to pleonite 6 or even up to apex of endopod of uropods. Its exopod with basal segment longest, second segment longer than third. Subterminal segment of exopod with a very long seta bearing dense series of minute bristles along its distal $20-53 \%$; short terminal segment with shorter seta at tip, this seta with characteristic set of barbs (Fig. 12K) along its distal third. Endopod with its largest distal seta 1.2-2.0 times endopod length. Sympod with field of scales on its medial widening, or in analogous position upon missing widening. Scutellum paracaudale (Fig. 13B) subtriangular, apically pointed; upper margin concave, lower margin convex. Endopod of uropods (Fig. 13C) 1.0-1.3 times as long as pleonite 6, exopod 1.6-1.9 times pleonite 6. Length of exopod 8-10 times its maximum width. Exopod extends 0.3 times its length beyond endopod or 0.6-0.7 times beyond telson; endopod 0.4-0.6 times its length beyond telson. Telson (Fig. 13D) $0.4-0.5$ times as long as exopod of uropods, $0.6-0.8$ times endopod or $0.7-0.9$ times pleonite 6 .

Statoliths. Composed of fluorite; shape ellipsoidal to spherical in dorsal view (Fig. 13C), discoidal in lateral view, maximum diameter 126-188 $\mu \mathrm{m}$, thickness $62-97 \mu \mathrm{m}$, measured in 10 adults. Tegmen moderately, though always distinctly convex; fundus weakly concave. Sagittal section very similar to that figured by Wittmann et al. (1993: Fig. 6P) for Heteromysis formosa. Statolith formula $2+3+$ $(0-1)+(4-13)+(6-12)=19-25$.

Nauploid LaRvae. As in M. columbiae (Fig. 13H, J).

\section{Distribution and habitat}

In euhaline, sublittoral to littoral waters of Curaçao and Bonaire, both islands at $12^{\circ} \mathrm{N}$. The new species forms swarms during the day, hovering closely above the sea floor at a depth of $0-26 \mathrm{~m}$. Also found near shore boulders, around and off piers.

\section{Species not assigned to any subgenus}

\section{Mysidium iliffei Băcescu, 1991}

\section{Mysidium iliffei Băcescu, 1991: 3-5.}

Mysidium illifei - Băcescu 1991: fig. 1A-I (invalid spelling variant). Mysidium iliffei - Ortiz et al. 2017a: table 1; 2017b: 76. — Ortiz \& Lalana 2018: 80.

\section{Material examined}

No material available, not assigned to any subspecies: see Discussion.

\section{Type locality}

Băcescu (1991) indicated "Jamaica, St. D, 90.026 Sa Rba" as sampling site of the types.

\section{Revised definition}

Adapted to the scheme in Table 2 by using published data (Băcescu 1991) on adult females and subadult males: Mysidium with cornea calotte-shaped in dorsal view; diameter 1.5 times as long as terminal segment of antennular trunk. Anterior margin of carapace rounded. First to third segments occupy 57\%,13\% and 30\% total length of antennular trunk, respectively. Length of antennal scale six times maximum width, scale not reaching beyond antennular trunk. Carpopropodus three-segmented in 
thoracic endopod 3, and two-segmented in endopod 8. Basal segment occupies 0.4 times total length of carpopropodus of endopod 3. Uropodal endopod 0.8 times as long as exopod. Telson subrectangular with apical cleft. Telson length 1.6 times maximum width near basis. Its lateral margins slightly tapering and smooth along proximal 56-63\%; distal portion of each margin with dense continuous series of about 9-11 acute laminae. Subtriangular apical cleft penetrating 11\% telson length; cleft separating two broadly rounded, apical lobes; cleft and terminal portion of lobes densely lined in continuous series by about 17-22 acute laminae. Telson with a total of about 35-42 laminae.

\section{Distribution and habitat}

Only known from type locality. Băcescu (1991) reported T. Iliffe as collector, so the positional data are interpreted by the present authors according to a copy of the sampling protocol submitted by courtesy of Tom Iliffe: Jamaica, Westmoreland Parish, Negril, Joseph's Caves, station 90.026, sea cave with swarm of mysids congregated at the cave entrance, collected from water column and sand bottom at depths of 1-3 m, 26 June 1990, leg. Tom Iliffe. Coordinates estimated by the present authors are $18.2680^{\circ} \mathrm{N}$, $78.3681^{\circ} \mathrm{W}$ at the entrance of this touristic cave. Băcescu (1991) reported M. cubanense to co-occur with $M$. iliffei at this station.

\section{Key to the subgenera and species of Mysidium Dana, 1852}

Anisomysini with well-developed eyes. Antennal scale lanceolate, without spines, but setose all around, with small terminal segment. Thoracopods essentially normal, endopods with 2- or three-segmented carpopropodus. All pleopods of females and pleopods 1-3, 5 of males reduced, uniramous, unsegmented. Fourth male pleopod longest, biramous with setose, unsegmented endopod and with 3- or 4-segmented exopod; subterminal and terminal segments of exopod each ending in large modified seta. Uropods with setose margins, without spines. Telson longer than broad, with entire or incised terminal margin; with spines and laminae only on distal half. Genus Mysidium Dana, 1852 (endemic in tropical to subtropical, mainly euhaline, also metahaline coastal waters of the East Pacific at $21-26^{\circ} \mathrm{N}$ and the West Atlantic from $32^{\circ} \mathrm{N}$ to $24^{\circ} \mathrm{S}$, including Gulf of California, Gulf of Mexico and Caribbean)

1. Telson linguiform to subrectangular, terminally not emarginated or at most with a rounded, shallow indentation; male pleopod 4 with four-segmented exopod

- Telson with distinct apical cleft separating two broadly rounded, apical lobes .............................. 2

2. Antennal scale not extending beyond antennular trunk ............yysidium iliffei Băcescu, 1991 (from entrance of a sea cave in Jamaica, $18^{\circ} \mathrm{N}$; poorly known, therefore not assigned to any subgenus)

- Antennal scale extending well beyond antennular trunk; male pleopod 4 with three-segmented exopod: Orientomysidium Wittmann subgen. nov.

3. Sympod of male pleopod 4 with strong endite at $2 / 5$ sympod length from basis; both sexes with blunt laminae on terminal margins of telson and its cleft

Mysidium (Orientomysidium) columbiae (Zimmer, 1915) comb. nov. (Bahamas, Caribbean, southern Gulf of Mexico, coast of Brazil, $24^{\circ} \mathrm{N}$ to $8^{\circ} \mathrm{S}$ )

- Endite of sympod of male pleopod 4 reduced to indistinct projection; both sexes with acute laminae on terminal margins of telson and its cleft ......

Mysidium (Orientomysidium) antillarum Wittmann sp. nov. (Curaçao and Bonaire, $12-13^{\circ} \mathrm{N}$ )

4. Thoracic endopod 3 with two-segmented carpopropodus; subterminal segment of exopod of male pleopod 4 with bifid, modified seta Occimysidium Wittmann subgen. nov. (Mysidium (Occimysidium) pumae Ortiz, Hendrickx \& Winfield, 2017, Gulf of California, $23^{\circ} \mathrm{N}$ ) 
- Thoracic endopod 3 with three-segmented carpopropodus; subterminal segment of exopod of male pleopod 4 with unbranched, modified seta: subgen. Mysidium Dana, 1852 ................................... 5

5. Telson terminally with a shallow, rounded indentation ................................ Mysidium (Mysidium) gracile (Dana, 1852) (Bermuda, Caribbean, Gulf of Mexico, coast of Brazil, $32^{\circ} \mathrm{N}$ to $24^{\circ} \mathrm{S}$ )

- Telson terminally not emarginated 6

6. Telson spatulate, its terminal portion triangular with rounded tip

Mysidium (Mysidium) triangulare Wittmann sp. nov. (Curaçao, $12^{\circ} \mathrm{N}$ )

- Telson with traverse or with convex, continuously rounded terminal margin ................................. 7

7. Median segment of mandibular palp without setae on outer margin; basal segment of carpopropodus of thoracic endopod 3 measures 0.6 times total length of carpopropodus

Mysidium (Mysidium) rickettsi Harrison \& Bowman, 1987 (Pacific coast of Mexico, 21-26 N)

- Median segment of mandibular palp with setae on both margins; basal segment of carpopropodus of thoracic endopod 3 is half total length of carpopropodus

8. Pleopod 1 rod-like in both sexes; unevenly rounded hump on outer face of distal segment of maxillula

Mysidium (Mysidium) rubroculatum Băcescu \& Ortiz, 1984 (Gulf of Mexico, Cuba, 22-23ㅇN)

- Pleopod 1 bilobate in both sexes; about evenly rounded hump on outer face of distal segment of maxillula

9. Cornea diameter $<2.5$ times as long as terminal segment of antennular trunk

Mysidium (Mysidium) integrum

W.M. Tattersall, 1951 (Bermuda, Bahamas, Caribbean, Gulf of Mexico, coast of Brazil, $32^{\circ} \mathrm{N}$ to $23^{\circ} \mathrm{S}$ )

- Cornea diameter $>2.5$ times as long as terminal segment of antennular trunk ................. Mysidium

(Mysidium) cubanense Băcescu \& Ortiz, 1984 (Gulf of Mexico, Cuba, Bonaire, Curaçao, 12-23N)

\section{Discussion}

\section{Formal validity of the taxon Mysidium Dana, 1852}

Dana (1850) fixed the name Mysidia without indication of gender; this taxon is today considered to be a junior homonym of the planthopper genus Mysidia Westwood, 1840. Dana $(1852: 638,653)$ replaced his Mysidia by assignment of the type species to Macromysis White, 1847 , today considered a subjective junior synonym of the European mysid genus Praunus Leach, 1814. Upon citing his own contribution from 1850 in a total of two footnotes on the same pages, he retrospectively changed Mysidia to Mysidium (Dana 1852: 638, 653), from today's point of view publishing the new name in synonymy. One cannot exclude that he actually intended to correct the nominative plural to become the nominative singular according to the second declension of neutral Latin substantives, rather than fixing a nomen novum by retrospective, contradictory means. Regardless, Czerniavsky (1882: 16) and most subsequent authors accepted Mysidium Dana, 1852, as a valid taxon, thus making it available according to Article 11.6.1 of the nomenclatorial code (ICZN 1999).

\section{Differentiation within the genus Mysidium Dana, 1852}

Most interspecific differences belong to an ensemble of the 25 morphological criteria listed in Table 2 as being sufficient for the distinction of all the here acknowledged species of the genus. The numbers of morphological differences per species pair are summarized in Table 3 as a derivate from Table 2. Not considering the poorly known M. iliffei Băcescu, 1991, three species groups are distinguished whereby the respective numbers of differences range from 1-6 for within-group differences and 9-15 
Table 3. Number of documented morphological differences between and within the proposed subgenera of Mysidium Dana, 1852. Bold print marks differences between species pertaining to different subgenera.

\begin{tabular}{|c|c|c|c|c|c|c|c|c|c|}
\hline & 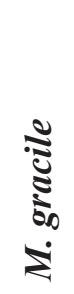 & 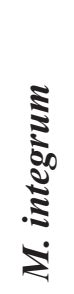 & 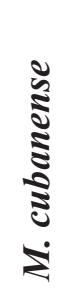 & 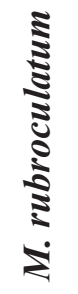 & 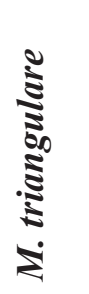 & 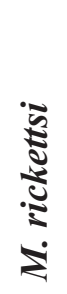 & 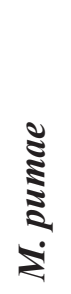 & 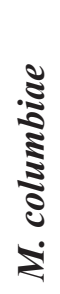 & 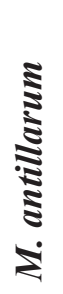 \\
\hline Mysidium (Mysidium) gracile & - & & & & & & & & \\
\hline Mysidium (Mysidium) integrum & 3 & - & & & & & & & \\
\hline Mysidium (Mysidium) cubanense & 3 & 1 & - & & & & & & \\
\hline Mysidium (Mysidium) rubroculatum & 4 & 3 & 2 & - & & & & & \\
\hline Mysidium (Mysidium) triangulare & 2 & 3 & 3 & 5 & - & & & & \\
\hline Mysidium (Mysidium) rickettsi & 6 & 3 & 5 & 5 & 5 & - & & & \\
\hline Mysidium (Occimysidium) pumae & 11 & 9 & 9 & 10 & 11 & 13 & - & & \\
\hline Mysidium (Orientomysidium) columbiae & 12 & 13 & 12 & 11 & 10 & 12 & 15 & - & \\
\hline Mysidium (Orientomysidium) antillarum & 11 & 12 & 13 & 14 & 13 & 13 & 12 & 2 & - \\
\hline Mysidium iliffei & 5 & 7 & 6 & 7 & 5 & 8 & 6 & 5 & 5 \\
\hline
\end{tabular}

for between-group differences. The great number of between-group differences strongly supports three different morphological entities, here established as the subgenera Mysidium Dana, 1852, Occimysidium subgen. nov. and Orientomysidium subgen. nov. The main differences between these taxa are emphasized in the above diagnoses of subgenera.

\section{Differentiation within the nominotypical subgenus Mysidium Dana, 1852}

Within this cluster of six very similar species, M. gracile is essentially distinguished by a weak, but distinct indentation of the terminal margin of the telson and by large setae on the mediodistal extension of the male antennular trunk, M. cubanense by the enormous eyes, M. rickettsi by the absence of setae on the outer margin of the median segment of the mandible in combination with a comparatively long basal segment of the carpopropodus of the third thoracic endopod, M. integrum by a traverse to weakly convex terminal margin of the telson in combination with a great number of spines on the lateral margins and $M$. rubroculatum by a more unevenly rounded hump on the outer face of the terminal segment of the maxillula and more rod-like first pleopod. Within its subgenus, $M$. triangulare sp. nov. is unique by a triangular apical portion of the telson, and shows on the average the greatest numbers of setae on the mediodistal extension of the male antennular trunk and of laminae on the terminal margin of the telson. Conversely, it shows the fewest spines on the lateral margins of the telson.

\section{Differentiation of the new subgenus Occimysidium}

In addition to the ensemble of diagnostic characters indicated above for this monotypic subgenus, its type species, M. pumae, differs from all species of the remaining subgenera by acute laminae rather than spines on the lateral margins of the telson; this feature, however, is shared with $M$. iliffei. The lateral telson margins in $M$. pumae bear more laminae than the laminae or spines in the remaining species 
(exception: number of spines in $M$. integrum). The basal segment of the carpopropodus of the third thoracic endopod is longer in M. pumae than in the remaining species of the genus.

\section{Differentiation within the new subgenus Orientomysidium}

Only M. columbiae, $M$. antillarum sp. nov. and $M$. iliffei show a telson with a distinct, subtriangular cleft, separating two rounded latero-apical lobes; cleft and terminal portions of the lobes are densely furnished with acute or blunt laminae, while the armature of the lateral margins differs more strongly between species. Additional exclusive features are shared by M. columbiae and M. antillarum sp. nov. , but are unknown in $M$. iliffei: third and fifth male pleopods longer and more slender compared to that in the remaining species of the genus. Serrated setae (Figs 9D, 12B) are present on the merus of the third thoracic endopod in M. columbiae and M. antillarum sp. nov. , but this detail is unknown in M. iliffei and $M$. rickettsi, and such modified setae are absent in the remaining six species of the genus. In addition, M. columbiae and M. antillarum sp. nov. share a strong endite (Figs 9G, 12J) on the third male pleopod with M. pumae, as opposed to the medial widening (Figs 1E, 2E, 3E, 4E, 7K) visible in M. gracile, $M$. integrum, $M$. cubanense, $M$. rubroculatum, and $M$. triangulare sp. nov. They also share on average fewer setae on the mediodistal extension of the antennular trunk compared to the latter five species (Figs 9B, 10B versus Figs 1B, 2B, 3B, 4B, 5B).

The sympod of the fourth male pleopod in M. columbiae differs from that in all remaining species of the genus by a strong endite at $2 / 5$ distance from the basis (reservation: this feature is not clear in M. iliffei). In $M$. antillarum sp. nov. this endite is reduced to a low, sometimes indistinct projection. A very short endite was figured by Brattegard (1969: fig. 27E) for material from the Bahamas, reported by him as M. columbiae, now considered as potentially indicative of $M$. antillarum $\mathrm{sp}$. nov. Mysidium columbiae shares this series of setae on the rostral face of this sympod only with M. antillarum sp. nov. Zimmer (1915a: fig. 28) did not illustrate most of these setae for M. columbiae because he drew the opposite face of the sympod. It remains unclear where the most proximal seta in his figure inserts. Series of such rostrally inserting setae were identified by us in the types and in all additional specimens examined in this respect. We therefore included these setae in the revised definition of M. columbiae. In addition to the different size of the endite of the sympod of male pleopod 4, both sexes of $M$. antillarum sp. nov. differ from M. columbiae by more acute laminae on the terminal margin of the telson including the cleft. Further differences the new species shows are typically a longer, more slender appendix masculina, more spines on the lateral margins of the telson, and fewer laminae on the terminal margin.

\section{Definition and availability of Mysidium iliffei Băcescu, 1991}

Among the characters described by Băcescu (1991), two striking ones are clearly out of the ranges of variation found in $M$. columbiae and $M$. antillarum sp. nov.: (1) antennal scale stouter and not extending beyond antennular trunk, and (2) lateral margins of telson with laminae rather than spines.

A potential third point is not clear for M. iliffei: Băcescu (1991) wrote "l'article basal du IVe pléopode $\widehat{~}$

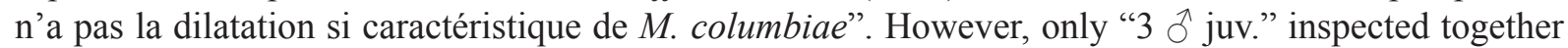
with "le IVe pléopode $\widehat{o}$ dépasse à peine le milieu du Ve pléonite" suggest that he had treated 'subadult' males in the present terminology. Features of this pleopod given by Ortiz et al. (2017b) in the diagnosis of M. iliffei are based (Manuel Ortiz, pers. comm.) only on the unclear data given by Băcescu (1991). As shown in the above description of M. columbiae, the widening (endite) of the sympod of the fourth male pleopod is missing or unapparent in early subadults. Accordingly, the absence of an endite in subadults cannot be employed as being diagnostic of M. iliffei versus M. columbiae.

Attempts to obtain material of M. iliffei for study failed. Băcescu (1991) had indicated the Grigore Antipa Museum, Bucharest, as the deposition site of the types. However, the types are not in this collection according to the holdings listed by Petrescu \& Wittmann (2009). An additional check in 2018 confirmed 
that there is neither any entry in the inventory nor any corresponding material in the collection (Melanya Stan and Iorgu Petrescu, pers. comm.). An online request (platform 'CRUST-L', 8 Mar. 2018) to the crustaceology community yielded no conclusive information about a potential alternative deposition of the types and any other potential material of this taxon. No additional samples were published after the first description by Băcescu (1991). Accordingly, M. iliffei is currently not assigned to any subgenus due to insufficient knowledge and inaccessibility of material.

\section{Acknowledgements}

The authors are greatly indebted to Manuel Ortiz for morphological information about Mysidium iliffei and to Tom Iliffe for sampling data of the types of this species; to Iorgu Petrescu, Serban Sarbu and Melanya Stan for the effort they made searching for these types. Great thanks are extended to Iorgu Petrescu, Kathrin Philipps-Bussau, Martin Schwentner and Petra Wagner for managing loan requests and sending museum specimens of Mysidium species for examination. The present work would not have been possible without the valuable support by all these people. The second author wishes to thank Steven Weinberg and the staff of CARMABI for their support during his visit there in August 1997. This study received Portuguese national funds through FCT - Foundation for Science and Technology through project UID/Multi/04326/2013.

\section{References}

Almeida Prado M.S. de 1974. Sistemática dos Mysidacea (Crustacea) na região de Cananéia. Boletim do Instituto Oceanográfico, S. Paulo 23: 47-87. https://doi.org/10.1590/S0373-55241974000100004

Ambler J.W.,Alcala-Herrera J. \& Burke R. 1994. Trophic roles of particle feeders and detritus in a mangrove island prop root ecosystem. Hydrobiologia 292 (1): 437-446. https://doi.org/10.1007/BF00229970

Ariani A.P., Wittmann K.J. \& Franco E. 1993. A comparative study of static bodies in mysid crustaceans: Evolutionary implications of crystallographic characteristics. Biological Bulletin 185: 393-404. https://doi.org/10.2307/1542480

Băcescu M. 1954. Crustacea. Mysidacea. Fauna Republicii Populare Romîne 4 (3), Editura Academiei Republicii Populare Romîne, Bucureşti.

Băcescu M. 1991. Mysidium iliffei n.sp. et Amathimysis sarbui n.sp., Mysidacés nouveaux dans le secteur des Antilles. Revue roumaine de Biologie - Biologie animale 36 (1-2): 3-8.

Băcescu M. \& Ortiz M. 1984. Contribution to the knowledge of the Mysidacea (Crustacea) of the Cuban insular shelf waters. Travaux du Muséum d'Histoire naturelle «Grigore Antipa» 26: 15-23.

Bainbridge R. \& Waterman T.H. 1957. Polarized light and the orientation of two marine Crustacea. The Journal of Experimental Biology 34 (3): 342-364.

Bainbridge R. \& Waterman T.H. 1958. Turbidity and the polarized light orientation of the crustacean Mysidium. The Journal of Experimental Biology 35 (3): 487-493.

Banner A.H. 1954. The Mysidacea and Euphausiacea. In: Galtsoff P.S. (ed.) Gulf of Mexico, its Origin, Waters, and Marine Life. Fishery Bulletin 55: 447-448.

Brattegard T. 1969. Marine biological investigations in the Bahamas 10. Mysidacea from shallow water in the Bahamas and southern Florida. Part 1. Sarsia 39: 17-106.

https://doi.org/10.1080/00364827.1969.10411155

Brattegard T. 1970. Mysidacea from shallow water in the Caribbean Sea. Sarsia 43: 111-154. https://doi.org/10.1080/00364827.1970.10411174 
Brattegard T. 1973. Mysidacea from shallow water on the Caribbean coast of Colombia. Sarsia 54: 1-65. https://doi.org/10.1080/00364827.1973.10411249

Brattegard T. 1974a. Additional Mysidacea from shallow water on the Caribbean coast of Colombia. Sarsia 57: 47-86. https://doi.org/10.1080/00364827.1974.10411270

Brattegard T. 1974b. Mysidacea from shallow water on the Caribbean coast of Panama. Sarsia 57: 87-108. https://doi.org/10.1080/00364827.1974.10411271

Brattegard T. 1975. Shallow-water Mysidacea from the Lesser Antilles and other Caribbean regions. Studies Fauna Curaçao 47: 102-115.

Bullard S.G. \& Hay M.E. 2002. Plankton tethering to assess spatial patterns of predation risk over a coral reef and seagrass bed. Marine Ecology Progress Series 225: 17-28. https://doi.org/10.3354/meps225017

Buskey E.J. 1998. Energetic cost of position-holding behaviour in the planktonic mysid Mysidium columbiae. Marine Ecology Progress Series 172: 139-147. https://doi.org/10.3354/meps172139

Buskey E.J. 2000. Role of vision in the aggregative behavior of the planktonic mysid Mysidium columbiae. Marine Biology 137: 257-265. https://doi.org/10.1007/s002270000361

Costa H.R. da 1964. Notas sôbre os Mysidacea da Costa Brasileira. Boletim do Museu Nacional, Nuova Série-Zoologia 247: 1-9.

Czerniavsky V. 1882. Monographia Mysidarum inprimis Imperii Rossici (marin., lacustr. et fluviatilium). Fasc. 1. Trudy Sankt-Peterburgskago obshchestva estestvoispytatelei 12 (2): 1-170.

Czerniavsky V. 1887. Monographia Mysidarum inprimis Imperii Rossici (marin., lacustr. et fluviatilium). Fasc. 3. Trudy Sankt-Peterburgskago obshchestva estestvoispytatelei 18: 1-102.

Dana J.D. 1850. Synopsis generum Crustaceorum ordinis "Schizopoda". American Journal of Science and Arts, Series 2, 9 (25): 129-133.

Dana J.D. 1852. Crustacea. Part I. United States Exploring Expedition during the Years 1838, 1839, 1840, 1841, 1842 under the Command of Charles Wilkes, U. S. N. Vol. XIII (I). C. Sherman, Philadelphia.

Dana J.D. 1853. On the Classification and Geographical Distribution of Crustacea: from the Report on Crustacea of the United States Exploring Expedition, under Captain Charles Wilkes, U.S.N., during the Years 1838-1842. C. Sherman, Philadelphia.

Dana J.D. 1855. Atlas. Crustacea. United States Exploring Expedition during the Years 1838, 1839, 1840, 1841, 1842. Vol. 13. C. Sherman, Philadelphia.

Davis C.C. 1966. A study of the hatching process in aquatic invertebrates. XXII. Multiple membrane shedding in Mysidium columbiae (Zimmer) (Crustacea: Mysidacea). Bulletin of Marine Science 16 (1): 124-131.

Duman-Scheel M. \& Patel N.H. 1999. Analysis of molecular marker expression reveals neuronal homology in distantly related arthropods. Development 126 (11): 2327-2334.

Duman-Scheel M., Pirk1 N. \& Patel N.H. 2002. Analysis of the expression pattern of Mysidium columbiae wingless provides evidence for conserved mesodermal and retinal patterning processes among insects and crustaceans. Development Genes and Evolution 212 (3): 114-123. https://doi.org/10.1007/s00427-002-0215-6

Emery A.R. 1968. Preliminary observations on coral reef plankton. Limnology and Oceanography 13 (2): 293-303. https://doi.org/10.4319/1o.1968.13.2.0293 
Escobar-Briones E. 2002. Lophogastrida y Mysida. In: Morrone Lupi J.J., Llorente-Bousquets J.E. \& Ponce H. (eds) Biodiversidad, taxonomía y biogeografía de artrópodos de México: Hacia una síntesis de su conocimiento. Vol. III: 291-304. México D.F., Universidad Nacional Autónoma de México.

Escobar-Briones E. \& Soto L.A. 1991. Biogeografia de los Misidáceos (Crustacea: Peracarida) del Golfo de México. Caribbean Journal of Science 27 (1-2): 80-89.

Esteves-Astudillo M., Narváez-Ruiz M., Ariza-Arredondo L., Núñez-Peñalver J., MartínezMendoza A. \& Marín-Espinoza B. 2017. Misidáceos (Crustacea: Malacostraca), de la zona de rompiente de Playa Tunantal, Golfo de Cariaco, Venezuela. Boletín del Instituto Oceanográfico de Venezuela 56 (2): $57-65$.

Ferrari F.D. 2001. The work of Thomas Elliot Bowman III (1918-1995). Crustacean Issues 13: 1-17.

Fukuoka K. 2006. Taxonomy and geographic distribution of mysids of the tribe Mysini (Crustacea: Mysida: Mysidae). TAXA, Proceedings of the Japanese Society of Systematic Zoology 21: 13-18. https://doi.org/10.19004/taxa.21.0_13

Gerstaecker A. \& Ortmann A.E. 1901. Malacostraca. 3. Unterordnung Schizopoda. In: Bronn H.G. (ed.) Klassen und Ordnungen des Tierreichs. Vol. 5, Abt. 1, pt. 2: 602-686. C.F. Winter'sche Verlagsbuchhandlung, Leipzig.

Gómez-Gutiérrez J., Funes-Rodríguez R., Arroyo-Ramírez K., Sánchez-Ortíz C.A., Beltrán-Castro J.R., Hernández-Trujillo S., Palomares-García R., Aburto-Oropeza O. \& Ezcurra E. 2014. Oceanographic mechanisms that possibly explain dominance of neritic-tropical zooplankton species assemblages around the Islas Marías Archipelago, Mexico. Latin American Journal of Aquatic Research 42 (5): 1009-1034. https://doi.org/10.3856/vol42-issue5-fulltext-7

Goodbody I. 1965. Continuous breeding in populations of two tropical crustaceans, Mysidium columbiae (Zimmer) and Emerita portoricensis Schmidt. Ecology 46: 195-197. https://doi.org/10.2307/1935274

Hahn P. \& Itzkowitz M. 1986. Site preference and homing behavior in the mysid shrimp, Mysidium gracile (Dana). Crustaceana 51 (2): 215-219. https://doi.org/10.1163/156854086X00700

Harrison E.B. \& Bowman T.E. 1987. Mysidium rickettsi, a new species of mysid from the Gulf of California (Crustacea: Mysidacea: Mysidae). Proceedings of the Biological Society of Washington 100 (3): 674-679.

ICZN (International Commission on Zoological Nomenclature). 1999. International Code of Zoological Nomenclature. $4^{\text {th }}$ edition. International Trust for Zoological Nomenclature, London. Available from http://www.nhm.ac.uk/hosted-sites/iczn/code/ [accessed 30 Jun. 2018].

Illig G. 1930. Die Schizopoden der Deutschen Tiefsee-Expedition. In: Chun C. (ed.) Wissenschaftliche Ergebnisse der Deutschen Tiefsee-Expedition auf dem Dampfer ,Valdivia“ 1898-1899. Vol. 22 (6): 397-620. Gustav Fischer Verlag, Jena.

Jander R. 1962. The swimming plane of the crustacean Mysidium gracile. Biological Bulletin 122 (3): 380-390. https://doi.org/10.2307/1539238

Kobusch W. 1998. The foregut of the Mysida (Crustacea, Peracarida) and its phylogenetic relevance. Philosophical Transactions of the Royal Society. B. Biological Sciences 353: 559-581. https://doi.org/10.1098/rstb.1998.0227

Markham J.C., Donath-Hernandez F.E., Villalobos-Hiriart J.L. \& Diaz-Barriga A.C. 1990. Notes on the shallow-water marine Crustacea of the Caribbean coast of Quintana Roo, Mexico. Anales del Instituto de Biologia Universidad Nacional Autonoma de Mexico, Serie Zoologia 61: 405-446. 
Mauchline J. 1972. The biology of bathypelagic organisms, especially Crustacea. Deep-Sea Research 19 (11): 753-780. https://doi.org/10.1016/0011-7471(72)90097-6

Mauchline J. 1973. The broods of British Mysidacea (Crustacea). Journal of the Marine Biological Association of the United Kingdom 53: 801-817. https://doi.org/10.1017/S0025315400022487

Mauchline J. 1980. The biology of mysids and euphausiids. In: Blaxter J.H.S., Russell F.S. \& Young M. (eds) Advances in Marine Biology. Vol. 18. Academic Press, London.

McFarland W.N. \& Kotchian N.M. 1982. Interaction between schools of fish and mysids. Behavioral Ecology and Sociobiology 11 (2): 71-76. https://doi.org/10.1007/BF00300094

Miyashita L.K. \& Calliari D. 2014. Revision of mysids (Crustacea: Peracarida: Mysida) zoogeographical distribution in the south-west Atlantic $\left(0^{\circ}\right.$ to $\left.40^{\circ} \mathrm{S}\right)$. Marine Biodiversity Records 7 (E5): 1-13. https://doi.org/10.1017/S1755267213001176

Modlin R.F. 1984. Mysidacea from the Florida Middle Ground, northeast Gulf of Mexico, with descriptions of three new species of Heteromysis and a key to the Heteromysini of the Western Atlantic. Journal of Crustacean Biology 4 (2): 278-297. https://doi.org/10.2307/1548026

Modlin R.F. 1987. Mysidacea from shallow waters in the vicinity of Carrie Bow Cay, Belize, Central America, with descriptions of two new species. Journal of Crustacean Biology 7: 106-121. https://doi.org/10.1163/193724087X00090

Modlin R.F. 1990. Observations on the aggregative behavior of Mysidium columbiae, the mangrove mysid. P.S.Z.N. I: Marine Ecology 11 (3): 263-275. https://doi.org/10.1111/j.1439-0485.1990.tb00244.x

Modlin R.F. 1993. Population parameters, life cycle, and feeding of Mysidium columbiae (ZIMMER) in the waters surrounding a Belizian mangrove cay. P.S.Z.N. I: Marine Ecology 14 (1): 23-34. https://doi.org/10.1111/j.1439-0485.1993.tb00362.x

Murano M. 1999. Mysidacea. In: Boltovskoy D. (ed.) South Atlantic Zooplankton. Vol. 2: 1099-1140. Backhuys Publishers, Leiden.

Ortiz M. 2001. Los invertebrados marinos, estuarinos y semiterrestres de la playa de Cojímar, en la costa norte de la provincia Ciudad de La Habana. Revista Investigaciones Marinas 22 (2): 93-102.

Ortiz M.\& Lalana R. 1988. Lista de especies y bibliografia de los crustáceos de Cuba. II. Cirripedia, Phyllocarida, Pancarida, Mysidacea, Tanaidacea y Cumacea. Revista Investigaciones Marinas 9 (2): $11-19$.

Ortiz M. \& Lalana R. 1997. Un nuevo aditamento para la colecta de misidaceos suprabentonicos (Crustacea), con red manual. Revista Investigaciones Marinas 18 (3): 187-190.

Ortiz M. \& Lalana R. 2018. Los Misidáceos (Lophogastrida, Stygiomysida y Mysida), de Cuba: Historia, claves dicotómicas, figuras y bibliografía. Revista Investigaciones Marinas 37 (2) (2017): 61-79.

Ortiz M., Lalana R. \& Varela C. 2006. Crustáceos no decápodos. Filo Arthropoda, Subfilo Crustacea. Lista de especies registradas en Cuba. In: Claro R. (ed.) Biodiversidad Marina de Cuba: 1-11. CDR, Instituto de Oceanología, La Habana, Cuba.

Ortiz M., Winfield I. \& Cházaro-Olvera S. 2012. Lista actualizada y clave ilustrada para los géneros de misidáceos (Crustacea, Peracarida) del Mar Intra-Americano. Revista Mexicana de Biodiversidad 83: 983-1003.

Ortiz M., Hendrickx M.E. \& Winfield I. 2017a. A new species of Mysidium (Peracarida: Mysida: Mysidae) from the eastern tropical Pacific. Journal of the Marine Biological Association of the United Kingdom 97 (1): 113-117. Published online in 2016. https://doi.org/10.1017/S0025315416000102 
Ortiz M., Hendrickx M., Winfield I. \& Cházaro-Olvera S. 2017b. The genus Mysidium Dana, 1852 (Crustacea, Peracarida, Mysida) in tropical America: Synthesis and identification key to species. Revista Investigaciones Marinas 37 (1): 69-85.

Petrescu I. \& Wittmann K.J. 2009. Catalogue of the Mysida type collection (Crustacea: Peracarida) from the "Grigore Antipa" National Museum of Natural History (Bucureşti). Travaux du Muséum national d'Histoire naturelle «Grigore Antipa» 52: 53-72.

Price W.W. 2004. An annotated checklist for the order Mysida (Crustacea: Malacostraca: Peracarida) from the Pacific coasts of the Americas (Alaska to Chile). In: Hendrickx M.E. (ed.), Contributions to the Study of East Pacific Crustaceans. Vol. 3: 53-77. Instituto de Ciencias del Mar y Limnologia, UNAM.

Price W.W. \& Heard R.W. 2004. Studies on the Crustacea of the Turks and Caicos Islands, British West Indies. V. Records of Mysids from Pine Cay, Fort George Cay, Water Cay, and Adjacent Waters. Gulf and Carribean Research 16 (2): 147-159. https://doi.org/10.18785/gcr.1602.03

Price W.W. \& Heard R.W. 2009. 53. Mysida (Crustacea) of the Gulf of Mexico. In: Felder D.L. \& Camp D.K. (eds) Gulf of Mexico - Origins, Waters, and Biota. Biodiversity. Vol. 1: 929-938. Texas A\&M Press, College Station.

Price W.W., McAllister A.P., Towsley R.M. \& DelRe M. 1986. Mysidacea from continental shelf waters of the northwestern Gulf of Mexico. Contributions in Marine Science 29: 45-58.

Price W.W., Heard R.W., Harris J.T. \& McCoy C.M.R. 2002. Crustacea of the Cayman Islands, British West Indies. I. Records of mysids from shallow water non-reef habitats. Gulf and Carribean Research 14: 35-52. https://doi.org/10.18785/gcr.1401.03

Price W.W., Heard R.W. \& Vargas R. 2009. Part 17. Shallow water mysids. In: Wehrtmann I.S. \& Cortés J. (eds) Marine Biodiversity of Costa Rica, Central America. Monographiae Biologicae 86: 229$236+$ CD with species list. https://doi.org/10.1007/978-1-4020-8278-8

Prieto A., Álvarez V. \& González L. 2009. Aspectos reproductivos de una población de Mysidium columbiae, Zimmer (1915) (Crustacea: Mysidacea) en Guaracayal, costa sur del Golfo de Cariaco, estado Sucre, Venezuela. Ciencia 17 (1): 33-41.

Quintero R.C. \& Zoppi de Roa E. 1977. Misidaceos de algunas regiones de Manglares de Venezuela. Acta biologica Venezuelica 9 (3): 259-270.

Randall J.E., Schroeder R.E. \& Stark W.A. 1964. Notes on the biology of the echinoid Diadema antillarum. Caribbean Journal of Science 4: 421-433.

Schlacher T.A., Wittmann K.J. \& Ariani A.P. 1992. Comparative morphology and actuopalaeontology of mysid statoliths (Crustacea, Mysidacea). Zoomorphology 112 (2): 67-79. https://doi.org/10.1007/BF01673808

Smith S.I. 1873. Notice of the Crustacea collected by Prof. C.F. Hartt on the coast of Brazil in 1867. Transactions of the Connecticut Academy of Arts and Sciences 2: 1-42, 1 pl. https://doi.org/10.5962/bhl.part.20634

Sorbe J.C., Martin A. \& Diaz Y. 2007. New records of Mysida (Crustacea: Peracarida) from shallow waters of the Caribbean coast of Venezuela. Marine Biology Research 3: 175-181. https://doi.org/10.1080/17451000701397513

Steven D.M. 1961. Shoaling behaviour in a mysid. Nature 192: 280-281.

https://doi.org/10.1038/192280b0

Tattersall W.M. 1951. A review of the Mysidacea of the United States National Museum. Bulletin of the United States National Museum 201: 1-292. https://doi.org/10.5962/bhl.part.16843 
Tattersall W.M. \& Tattersall O.S. 1951. The British Mysidacea. Ray Society, Monograph 136, The Ray Society, London.

Twining B.S., Gilbert J.J. \& Fisher N.S. 2000. Evidence of homing behavior in the coral reef mysid Mysidium gracile. Limnology and Oceanography 45 (8): 1845-1849.

https://doi.org/10.4319/lo.2000.45.8.1845

Waterman T.H. 1960. Interaction of polarized light and turbidity in the orientation of Daphnia and Mysidium. Zeitschrift für vergleichende Physiologie 43 (2): 149-172.

Whittington P.M. 2004. The development of the crustacean nervous system. In: Scholtz G. (ed.) Evolutionary Developmental Biology of Crustacea. Crustacean Issues 15: 135-167. A.A. Balkema, Rotterdam.

Wittmann K.J. 1981. Comparative biology and morphology of marsupial development in Leptomysis and other Mediterranean Mysidacea (Crustacea). Journal of Experimental Marine Biology and Ecology 52 (2-3): 243-270. https://doi.org/10.1016/0022-0981(81)90040-X

Wittmann K.J. 2008. Two new species of Heteromysini (Mysida, Mysidae) from the Island of Madeira (N.E. Atlantic), with notes on sea anemone and hermit crab commensalisms in the genus Heteromysis S. I. Smith, 1873. Crustaceana 81: 351-374. https://doi.org/10.1163/156854008783564037

Wittmann K.J. \& Griffiths C.L. 2018. A new species of Mysidopsis G.O. Sars, 1864 from the Cape Peninsula, South Africa, with supplementary descriptions of two other species and notes on colour and feeding apparatus (Mysida: Mysidae: Leptomysinae: Mysidopsini). Journal of Crustacean Biology 38 (2): 215-234. https://doi.org/10.1093/jcbiol/rux118

Wittmann K.J., Schlacher T.A. \& Ariani A.P. 1993. Structure of Recent and fossil mysid statoliths (Crustacea, Mysidacea). Journal of Morphology 215: 31-49. https://doi.org/10.1002/jmor.1052150103

Wittmann K.J., Ariani A.P. \& Lagardère J.-P. 2014. Orders Lophogastrida Boas, 1883, Stygiomysida Tchindonova, 1981, and Mysida Boas, 1883 (also known collectively as Mysidacea). In: Vaupel Klein J.C. von, Charmantier-Daures M. \& Schram F.R. (eds) Treatise on Zoology - Anatomy, Taxonomy, Biology. The Crustacea. Revised and updated, as well as Extended from the Traité de Zoologie, Vol. 4 Part B (54): 189-396, colour plates: 404-406. Koninklijke Brill NV, Leiden.

https://doi.org/10.1163/9789004264939_006

Wittmann K.J., Ariani A.P. \& Daneliya M. 2016. The Mysidae (Crustacea: Peracarida: Mysida) in fresh and oligohaline waters of the Mediterranean. Taxonomy, biogeography, and bioinvasion. Zootaxa 4142: 1-70. https://doi.org/10.11646/zootaxa.4142.1.1

Zimmer C. 1915a. Schizopoden des Hamburger Naturhistorischen (Zoologischen) Museums. Mitteilungen aus dem naturhistorischen Museum in Hamburg 32: 159-182.

Zimmer C. 1915b. Die Systematik des Tribus Mysini H.J. Hansen. Zoologischer Anzeiger 46 (7): 202216.

Zimmer C. 1918. Neue und wenig bekannte Mysidaceen des Berliner Zoologischen Museums. Mitteilungen aus dem Zoologischen Museum in Berlin 9: 13-26.

Zoppi de Roa E. \& Alonso P. 1997. Distribution of Mysidium integrum (Tattersall) (Crustacea-Mysidacea) in Venezuelan coral habitats. Studies on the natural history of the Caribbean region 73: 55-62.

Zoppi de Roa E., Alonso P. \& Delgado M. 1989. Distribucion de misidaceos (Crustacea) en las costas de Venezuela. Boletin del Instituto Oceanográfico de la Universidad de Oriente 28 (1-2): 29-33. 
Manuscript received: 23 August 2018

Manuscript accepted: 7 November 2018

Published on: 5 February 2019

Topic editor: Rudy C.A.M. Jocqué

Desk editor: Kristiaan Hoedemakers

Printed versions of all papers are also deposited in the libraries of the institutes that are members of the EJT consortium: Muséum national d'Histoire naturelle, Paris, France; Meise Botanic Garden, Belgium; Royal Museum for Central Africa, Tervuren, Belgium; Royal Belgian Institute of Natural Sciences, Brussels, Belgium; Natural History Museum of Denmark, Copenhagen, Denmark; Naturalis Biodiversity Center, Leiden, the Netherlands; Museo Nacional de Ciencias Naturales-CSIC, Madrid, Spain; Real Jardín Botánico de Madrid CSIC, Spain; Zoological Research Museum Alexander Koenig, Bonn, Germany. 